\title{
Extensive profiling in Arabidopsis reveals abundant polysome-associated 24-nt small RNAs including AGO5-dependent pseudogene-derived siRNAs
}

\author{
ANTONIN MARCHAIS, ${ }^{1}$ CLÉMENT CHEVALIER, ${ }^{1}$ and OLIVIER VOINNET ${ }^{1}$ \\ Department of Biology, Swiss Federal Institute of Technology (ETH), 8092 Zürich, Switzerland
}

\begin{abstract}
In a reductionist perspective, plant silencing small (s)RNAs are often classified as mediating nuclear transcriptional gene silencing (TGS) or cytosolic posttranscriptional gene silencing (PTGS). Among the PTGS diagnostics is the association of AGOs and their sRNA cargos with the translation apparatus. In Arabidopsis, this is observed for AGO1 loaded with micro(mi)RNAs and, accordingly, translational-repression (TR) is one layer of plant miRNA action. Using AGO1:miRNA-mediated TR as a paradigm, we explored, with two unrelated polysome-isolation methods, which, among the ten Arabidopsis AGOs and numerous sRNA classes, interact with translation. We found that representatives of all three AGO-clades associate with polysomes, including the TGS-effector AGO4 and stereotypical 24-nt sRNAs that normally mediate TGS of transposons/repeats. Strikingly, approximately half of these annotated 24-nt siRNAs displayed unique matches in coding regions/introns of genes, and in pseudogenes, but not in transposons/repeats commonly found in their vicinity. Proteincoding gene-derived 24-nt sRNAs correlate with gene-body methylation. Those derived from pseudogenes belong to two main clusters defined by their parental-gene expression patterns, and are vastly enriched in AGO5, itself found on polysomes. Based on their tight expression pattern in developing and mature siliques, their biogenesis, and genomic/ epigenomic features of their loci-of-origin, we discuss potential roles for these hitherto unknown polysome-enriched, pseudogene-derived siRNAs.
\end{abstract}

Keywords: eukaryota; plants; polysome; small RNAs

\section{INTRODUCTION}

In eukaryotes, silencing small (s)RNAs, including micro(mi) RNAs and small-interfering(si)RNAs, regulate gene expression upon incorporation into effector proteins within the broadly conserved ARGONAUTE (AGO) family (Krol et al. 2010; He et al. 2011). RNA-directed DNA methylation (RdDM) in plants operates via the AGO4-clade AGOs encompassing AGO4, AGO6, and AGO9, which, loaded with transposable elements (TEs)- and repeat-derived siRNAs induce de novo DNA methylation at these loci often resulting in transcriptional gene silencing (TGS). RdDM involves large protein complexes containing de novo DNA methyl-transferases and the plant-specific DNA-dependent RNA polymerases PolIV and PolV, which enable transcription of epigenetically modified target loci. Short PollV transcripts are converted by RNA-DEPENDENT RNA POLYMERASE 2 (RDR2) into double-stranded RNA (dsRNA). The dsRNA is in turn processed by DICER-LIKE

\footnotetext{
${ }^{1}$ These authors contributed equally to this work. Corresponding author: voinneto@ethz.ch

Article is online at http://www.rnajournal.org/cgi/doi/10.1261/ rna.069294.118.
}

3 (DCL3), one of four Arabidopsis DCL RNaselll enzymes, into diagnostic 24-nt-long repeat-associated (rasi)RNAs (Law and Jacobsen 2010; Feng and Jacobsen 2011; Matzke et al. 2015). These are thought to guide AGO4/6/ 9 and associated DNA-methyl-transfereases onto nascent POLV-dependent transcripts actin as scaffolds for locusspecific epigenetic modifications. The 24-nt rasiRNAs constitute, by far, the largest bulk of endogenous sRNAs accumulating in healthy Arabidopsis, due to the highly repetitive nature of their loci-of-origin (Kasschau et al. 2007; Lelandais-Brière et al. 2010). Individual 24-nt rasiRNA species are, however, typically low in abundance at any given $T E /$ repeat locus due to the low transcriptional state imposed by RdDM and other epigenetic modifications.

Posttranscriptional gene silencing (PTGS) in healthy Arabidopsis involves mostly gene regulation via $\sim 21$-nt miRNAs produced from stem-loop-containing primary

\footnotetext{
C 2019 Marchais et al. This article is distributed exclusively by the RNA Society for the first 12 months after the full-issue publication date (see http://rnajournal.csh/p.org/site/misc/terms.xhtml). After 12 months, it is available under a Creative Commons License (Attribution-NonCommercial 4.0 International), as described at http:// creativecommons.org/licenses/by-nc/4.0/.
} 
transcripts by DCL1 and, occasionally, DCL4 (Rajagopalan et al. 2006; Voinnet 2009). miRNA effector proteins include the near-ubiquitously expressed AGO1 protein, and, secondarily, the AGO1-clade members AGO10 and AGO5 displaying a more tissue-specific expression (Borges et al. 2011; Tucker et al. 2012; Roodbarkelari et al. 2015; Zhou et al. 2015). miRNAs are diverse in sequences/transcription patterns and their steady-state accumulation can vary extensively from high abundance to bare detectability (Rogers and Chen 2013). AGO-miRNA pairs assembled as part of RNA-induced silencing complexes (RISCs) direct gene silencing of target transcripts bearing miRNAcomplementary sequences, mostly in coding regions. Some noncoding RNAs known as trans-acting (ta)siRNA primary transcripts (TAS) are converted into dsRNA by RDR6 upon interaction with 22-nt, asymmetric AGO1-bound miRNAs or with the AGO7-bound 21-nt miR390. DCL4 processes the dsRNA into a population of so-called secondary (2nd)siRNAs-the tasiRNAs-within a dominant sequence register, or "phase," ultimately enabling silencing of tasiRNA-complementary protein-coding transcripts (Felippes and Weigel 2009; Allen and Howell 2010; Vazquez et al. 2010). Some miRNAs also spawn RDR6-dependent tasiRNA-like molecules, called phasiRNAs, from protein-coding genes often belonging to large families, of which they enable the coordinated regulation via PTGS (Fei et al. 2013; Xia et al. 2015).

One mode of PTGS involves endonucleolytic cleavage, or "slicing" in the middle of target/sRNA base-paired regions, enabled by the catalytic core of slicing-proficient AGOs. Another mode of PTGS of target RNAs, mostly evident with endogenous miRNAs in plants (Chen 2004; Brodersen et al. 2008), is through translational repression (TR) possibly coupled to mRNA decay as in metazoan miRNA-mediated TR (Huntzinger and Izaurralde 2011; Fabian and Sonenberg 2012; Jonas and Izaurralde 2015). An implication of plant PTGS at the translation level is the association of the core components involved with monosomes and/or polysomes, first demonstrated in a low-throughput study of some AGO1-bound miRNAs (Lanet et al. 2009). Further work later revealed that miRNA-mediated TR via AGO1 occurs on membranes, likely predominantly the endoplasmic reticulum (ER) because the process requires the integral membrane protein ALTERED MERISTEM PROGRAM1 (AMP1) in association with this endomembrane compartment (Li et al. 2013). These findings echo related results obtained in the context of AGO2-mediated RNAi in mammalian cells (Stalder et al. 2013), and those of earlier studies in which a link between RNA silencing and membranes was established both in mammals and invertebrates (Gibbings et al. 2009; Lee et al. 2009). A similar connection was later found between membranes and AGO1-mediated PTGS in Arabidopsis (Brodersen et al. 2012), including in the context of RDR6dependent tasiRNA biogenesis (Jouannet et al. 2012).
Until recently, there was little insight into the extent to which plant miRNAs associate with polysomes, since the only available study (Lanet et al. 2009) had focused on a small selection of miRNA. A follow-up to the AMP1 study employing genome-wide deep-sequencing-based analyses showed that Arabidopsis miRNAs are generally enriched on membrane-bound polysomes (MBPs) compared to total polysomes, and that their MBP association depends on AGO1, which is itself membrane-bound in an RNA-independent manner (Li et al. 2016). This seminal study showed, unexpectedly, that slicing guided by the AGO1-miRNA RISC also occurs on MBPs thereby enabling tasiRNA/phasiRNA production from their MBP-associated noncoding and protein-coding precursors, respectively. Li et al. (2016) used a sedimentation-based method similar to that originally employed in the low-throughput analysis of Lanet et al. (2009), except that a step for microsome purification was added. Sedimentation-based fractionation of ribosomes according to their molecular mass is typically achieved by high-speed centrifugation through a $15 \%-$ $60 \%$ sucrose gradient (Mustroph et al. 2009). This accurately separates $40 \mathrm{~S}$ and $60 \mathrm{~S}$ ribosome subunits, monosomes (80S) and polysomes, although large molecular complexes might cosediment nonspecifically with ribosomes/polysomes, a potentially bias-inducing aspect of the method. The intrinsic resolution of the fractionation can also be limiting.

The present study was primarily aimed at expanding the scope of the previous analyses (Lanet et al. 2009; Li et al. 2016), which focused largely on AGO1-miRNA interactions with total polysomes and MBPs, respectively. Our larger aim was to comprehensively analyze which, among the multiple AGO effector proteins and the numerous cellular sRNA classes of Arabidopsis, interact with the translation machinery. We decided to employ at least one additional and alternative method to the sedimentation-based ribosome fractionation (thereafter referred to as "ribosome profiling" or "RP") used so far. The second method is the translating-ribosome affinity immunopurification (TRAP) (Zanetti et al. 2005; Mustroph et al. 2009; 2012; Juntawong et al. 2014). TRAP enables global translatome acquisition (Juntawong et al. 2014; Lin et al. 2014) and circumvents potential biases of RP including the nonspecific cosedimentation of high molecular weight complexes. However, TRAP requires the use of transgenic Arabidopsis lines in which a Flag-tagged version of the ribosomal protein RPL18 is overexpressed from the Cauliflower mosaic virus (CaMV) 35S_or from cell-specific_-promoters (Mustroph et al. 2009; Juntawong et al. 2014). As RPL18 incorporates into the 605 subunit, the method immunopurifies, in a single step, a mix of ribosomal complexes including monosomes and polysomes, together with associated cofactors. As such, it is therefore less discriminative than the sedimentation-based RP. However, given that both methods rely on completely distinct biochemical features, they provided a 
unique opportunity to conduct our global survey in the most unbiased manner, the results of which are presented here.

\section{RESULTS}

\section{Two complementary approaches to study AGO and sRNA association to ribosomes}

A preliminary comparative survey of the TRAP and RP methods focused on miRNAs and their main effector, AGO1.
TRAP coupled to northern analysis in inflorescences showed that only a small proportion of total AGO1 associates with Flag-RPL18, yet most miRNAs tested effectively coimmunopurified with ribosomal complexes, except miR173 and miR162, which were at or below detection limit (Fig. 1A). Two RP fractionation protocols were then tested. In the first one, used in the original study of Lanet et al. (2009), lysates were directly fractionated onto sucrose gradients (Fig. 1B, without sucrose cushion). This method was improved, however, to avoid collecting fractions from the bottom of the gradient-a source of variation in the
A

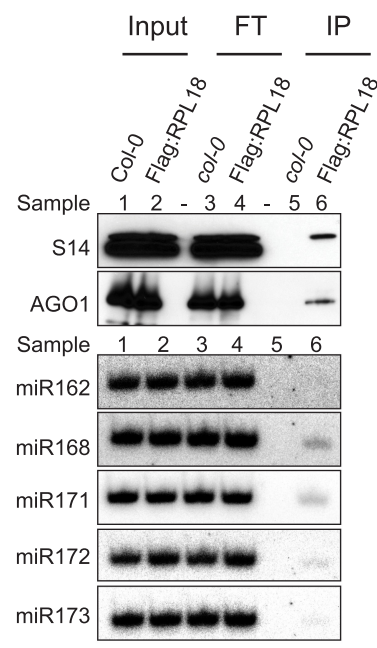

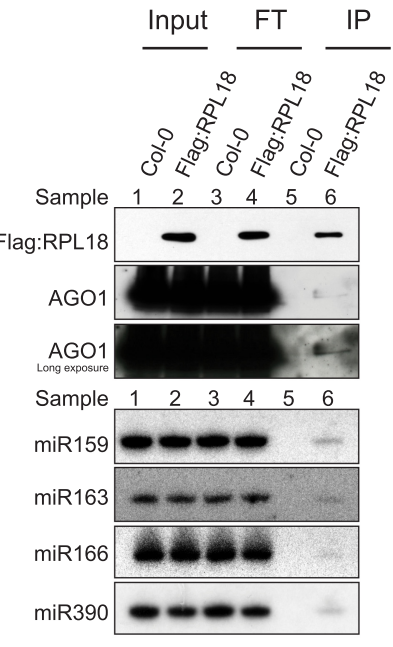

C

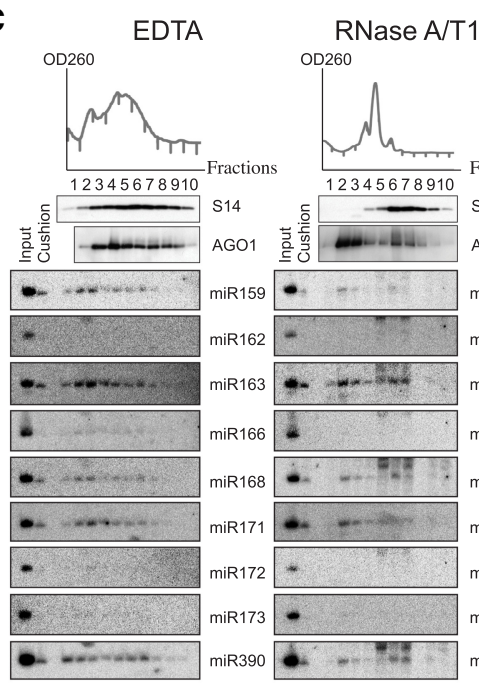

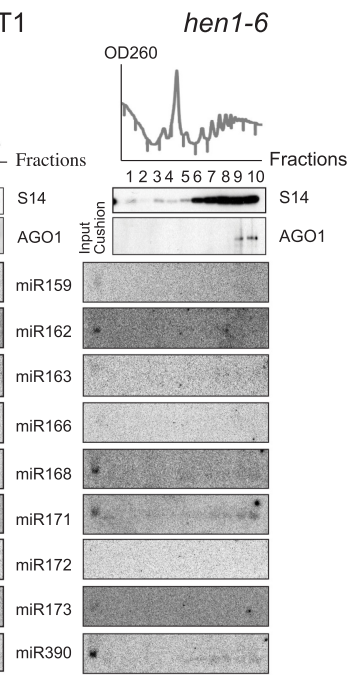

B
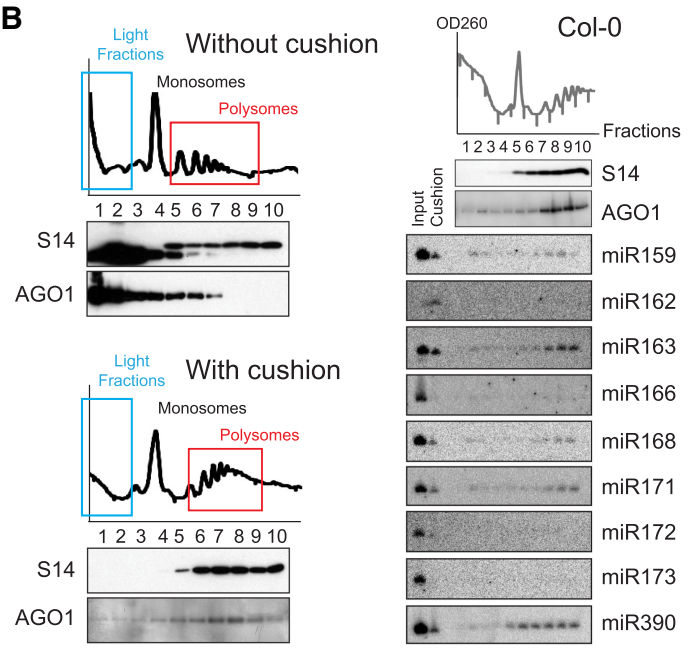

D

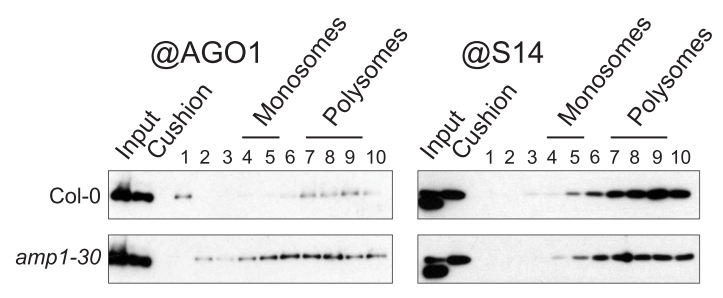

FIGURE 1. An AGO1 miRNA-RISC associates with ribosomal complexes in Arabidopsis. (A) Immunoprecipitation of ribosomal complexes from inflorescences via constitutive Flag-tagged RPL18 in two independent experiments (left and right panel); see main text for details. The abundance of AGO1 and selected miRNAs in the various fractions were measured by western and northern analysis using an antibody against native AGO1 and labeled complementary oligonucleotide probes, respectively. (FT) Flow-through, (IP) immunoprecipitation. (B, left, upper and lower panels) $\mathrm{RP}$ in inflorescences using two different protocols without or with sucrose cushion respectively; see main text for details. (Right panel) RP on $15 \%-$ $60 \%$ sucrose gradients was conducted in inflorescences. AGO1 and selected miRNA analyses were conducted as in $A$. (C) RP as described in $B$, but in WT or hen 1-6 inflorescences, in the presence of 40 mM EDTA or RNase A/T1. (D) Western analysis of AGO1 upon RP conducted as in B in amp1-30i Arabidopsis. Immunodetection of ribosomal protein S14 was used as a control in B-D to verify RP quality. All these experiments were produced in triplicate. 
collection process-and to expand the resolution to 10-13 instead of the original six fractions (see Materials and Methods). In the second method, high molecular weight ribosomal complexes were first enriched by ultracentrifugation through a $2 \mathrm{M}$ sucrose cushion (Fig. 1B, with cushion). Without cushion, soluble cytosolic proteins sedimented in light fractions 1-2, whereas polysomes, distributed in heavy fractions 5-9, were only represented at a low level. Adding the sucrose cushion step inverted this distribution, with soluble cytosolic proteins being depleted from the now underrepresented light fractions (Fig. 1B, compare blue squares) and polysomes significantly enriched in heavy fractions (Fig. 1B, compare red squares). Both protocols confirmed the cosedimentation of AGO1 with polysomes (Fig. 1B); but the first one also indicated that the majority of AGO1 cosediments with soluble, low-molecular weight (LMW) proteins and small complexes thereof, with only a comparatively small amount in the heavy monosomal/polysomal fractions 5-7 (Fig. 1B, without cushion). This observation therefore confirms the TRAP results (Fig. 1A) that only a small fraction of cellular AGO1 is potentially involved in translational regulations. This AGO1 pool is significantly enriched in polysomal fractions 7-9 obtained through the second RP protocol (Fig. 1B, with cushion), used, therefore, for the rest of our investigation.

As seen with TRAP, miR159, miR163, miR168, miR171, miR390 (of which the majority is AGO7-bound), and AGO1 cosedimented together with fractions 7-10 (Fig. $1 B, C)$ in RP, suggesting their polysomal enrichment. Also, as with TRAP, miR162 and miR173 were below northern detection in RP (Fig. 1B,C). The only discrepancy concerned miR166 and miR172, below detection in RP (Fig. 1B,C) but recovered by TRAP, albeit at low levels compared to their input levels (Fig. 1A). These two miRNAs might be poorly associated with the translation apparatus, and the additional sucrose gradient might cause their dilution among polysomal fractions, preventing their detection by RP. Their detection might be enhanced by addition of a further microsome separation step and MBP analyses (Li et al. 2016). For the most, nonetheless, the two approaches gave mutually consolidating results, providing a foundation for large-scale analyses via ultra-deep sequencing of sRNAs isolated through each method.

\section{AGO1 association with polysomes is mRNA- dependent, lost upon ribosome dissociation, and correlates with the cellular abundance of its SRNA cargoes}

We first tested if miRNA/AGO1 polysomal association indeed reflects targeting of translating mRNAs by an AGO1-RISC or, conversely, mere unspecific interactions between ribosomal subunits and silencing factors. RP was thus conducted with an extraction buffer (PEB) containing 40 mM EDTA (Fig. 1C), a $\mathrm{Mg}^{2+}$ chelator previously shown, in mammalian cells, to dissociate ribosomal subunits and deplete polysomes in heavy fractions as do classical puromycin treatments (Maroney et al. 2006; Del Prete et al. 2007). Puromycin treatments in seedlings/Arabidopsis cells were ineffective in our hands due, possibly, to penetration issues. Under $40 \mathrm{mM}$ EDTA conditions, the AGO1 and ribosomal protein $\mathrm{S} 14$ (directly reflecting the ribosomes' sedimentation state) fractionation profiles were distinctively different: S14 still accumulated in heavy fractions 6-9 yet AGO1 and miRNAs were shifted to light fractions 24 and $2-3$, respectively (Fig. $1 C$ ), suggesting that AGO1 polysomal association does not result from unspecific interactions. AGO1/miRNAs interaction with polysomes as part of a RISC is predicted to be target mRNA-dependent. To address this point, RNase A/T1 was added to the PEB buffer to degrade ribosome-bound mRNAs (Fig. 1C; Juntawong et al. 2014; 2015). AGO1 and miRNAs were shifted to the light fractions $1-3$, while S14 remained in fractions 6-9, possibly reflecting its residual association to cleaved mRNA fragments (Fig. 1C). These results concur with those of Li et al. (2016) showing that AGO1 association to MBPs depends largely on intact mRNAs. Collectively, the results from the EDTA and RNase A/T1 treatments are consistent with AGO1/miRNAs congregating on polysomes with their targets as part of functional RISCs.

As expected from their protective loading into AGOs including, chiefly, AGO1, the investigated miRNAs were unaffected by RNase A/T1 treatment, and so we resorted to genetics to verify if the mRNA-dependent AGO1 polysome cosedimentation requires AGO1 loading with miRNA/ sRNAs. We thus monitored the AGO1 polysomal distribution profile in Arabidopsis defective in miRNA biogenesis (dc/1-11), total sRNA stability (hen1-6), or mi/siRNA action (ago1-27) (Fig. 1C; Supplemental Fig. S1). In both dcl1-11 and ago1-27, several investigated miRNAs remained stable, possibly reflecting the hypomorphic nature of these mutations. In their MBP-focused analysis, Li et al. (2016) showed an effect of ago1-27 on miRNA recruitment to the ER. AGO1 was still detected on total polysomes in dc/1-11 and ago1-27, but parts of it were shifted to light fractions 1-2 in dcl1-11, suggesting that lack/reduction of some miRNAs decreases AGO1 association with the translation apparatus (Supplemental Fig. S1). The most dramatic effect was in hen 1-6, where most investigated miRNAs were destabilized and the bulk of AGO1 signal below detection along most of the profile (Fig. 1C). Unlike the miRNA-restricted effects of dc/1-11 and ago1-27 miRNArestricted effects, hen1-6 reduces stability of all Arabidopsis sRNAs, including endo-siRNA cargoes of AGO1. Although global lack of cargoes reduces AGO1 steady-state levels (Derrien et al. 2012), a fraction of it was still found in heavy fractions 9-10 in hen 1-6, possibly reflecting either (i) the presence, in the same fractions, of miRNAs, which, like miR171 or miR390, are less sensitive to HEN1 activity (Fig. 1C; Wang et al. 2015), or (ii) as 
proposed by Li et al. (2016), the miRNA-independent association of AGO1 with the polysome subset bound at the ER membrane. These might suffice to maintain a minimal pool of total polysome-associated AGO1. Collectively, these results therefore suggest that $\mathrm{AGO} 1$ association with total polysomes depends, at least partly, on the abundance and stability of its sRNA cargoes.

\section{Defect in AMP1 destabilizes AGO1 association with polysomes unlike expression of viral suppressors of RNA silencing}

miRNA-mediated TR is a complex and poorly understood process involving, in Arabidopsis, endo-membrane biology, possible trafficking and signaling via the cytoskeleton, as well as components of the mRNA decay pathway. Indeed, in addition to AGO1 and AGO10, TR-related factors include the GW-repeat-containing protein SUO (Yang et al. 2012), the microtubule-severing enzyme KATANIN (KTN), the decapping complex component VARICOSE (VCS), and the ER-/AGO1-associated integral membrane protein AMP1 (Brodersen et al. 2008; Várallyay et al. 2010; Li et al. 2013). No obvious variations in AGO1 polysomal association were observed in ktn and vcs compared to Col-0 (WT), as already observed in ago1-27 (Fig. 1B; Supplemental Fig. S1, and data not shown). In contrast, AGO1 consistently showed an unusual distribution in amp1-30, spanning fractions 2-10 (Fig. 1D), suggesting that part of the polysomal AGO1 was shifted to the monosomes and out of ribosomal complexes, to light fractions 2-3. This effect was AGO1-specific because distribution of S14 was unaltered in amp1-30. The partial effect observed on AGO1 might reflect that the strong requirement of AMP1 in TR was discovered upon MBP isolation, unlike total polysome isolation used here ( $\mathrm{Li}$ et al. 2013). Nonetheless, the results suggest that stable polysomal association of AGO1 relies, at least partly, on its genetic and/or physical interaction with AMP1. We also tested the effects of viral-encoded suppressors of RNA silencing (VSRs) on AGO1 polysome association, since an AGO1: siRNA antiviral RISC can also form in the cell. None of the VSRs tested affected AGO1 distribution in RP, however, and accordingly, none could be detected on monosomes or polysomes (Supplemental Fig. S2).

\section{The cohorts of polysome-associated sRNAs in Arabidopsis}

RP was conducted in inflorescences of WT Arabidopsis (ecotype Col-0) and sRNAs cosedimenting with either monosomal (4-5) or polysomal (7-9) fractions were separately subjected to deep-sequencing, as were sRNAs isolated in one TRAP experiment. Sequences from monosomal fractions were used for comparison to the polysome-specific sRNA signals, since total RNA cannot be used for normalization. Data were expressed in reads per million (RPMs) to compare the results within biological replicates and between the RP and TRAP methods. A bimodal sRNA length distribution was found in both RP sequencing libraries, with discrete peaks at 21-nt (miRNAs) and 24-nt (rasiRNAs), the sizes of the dominant Arabidopsis sRNA species; the sRNA length distribution obtained by TRAP was also bimodal, but the 24-nt peak was more pronounced (Supplemental Fig. S3A). The following sections provide a summary of the sRNA cohorts identified with both methods.

\section{Global comparison of sRNAs identified via the ribosomal profiling and TRAP approaches}

The libraries' qualities were first assessed by comparing abundance/size distribution of various RNA-derived fragments typically contaminating si/miRNA preparations. None of the five libraries showed specific size distribution biases for ribosomal RNAs (rRNAs), small nuclear RNAs (snRNAs) and small nucleolar RNAs (snoRNAs) (Fig. 2A; Supplemental Fig. S3A). A small tRNA peak in the 23-26nt size range was detected, however, possibly corresponding to AGO-loaded DCL3-processed tRNA fragments, of which some might contribute to TE silencing (Cognat et al. 2016; Martinez et al. 2017). rRNA reads abounded in all libraries, and at higher levels in the monosomal fractionations' replicates (Mono1 \& 2); tRNAs also predominated in all libraries, and were twice more abundant in polysomal fractions (Poly $1 \& 2$ ) and TRAP samples, consistent with their role in translation elongation. snoRNAs, although sequenced at low levels, were four- to 12-fold more abundant in TRAP; as previously noted (Juntawong et al. 2014). snRNA were the least abundant and nearly unaltered among the five libraries, which displayed, therefore, overall comparable qualitative features (Fig. 2A; Supplemental Fig. S3A). The miRNA size was centered on 21-nt in the five libraries and their levels were 1.6-fold higher in polysome library poly2 versus the two monosome libraries. Although miRNA levels were clearly underrepresented in TRAP versus all ribosomal fractions or total inflorescences (Fig. 2A; Supplemental Fig. S3A), northern analyses of distinct miRNAs isolated via either method showed comparable results, and all libraries contained near-identical miRNA populations (Supplemental Fig. S3B; Fig. 2A, lower right corner; Fig. 2B; Supplemental Fig. S3B, discussed in the next section). The tasi/ phasiRNA size was centered on 21-22-nt in all five libraries, with a slight enrichment in the poly2 versus the two monosome libraries (Fig. 2A). Inverted-repeat (IR)-derived siRNA distribution was biphasic, centered on 21-22-nt and 24-nt, reflecting IR processing by DCL4-DCL2 and DCL3, respectively, with the 24-nt fraction being enriched by approximately twofold in poly1, poly2 and TRAP libraries. Abundant TE- and genes/pseudogenes-derived 24-nt 
A
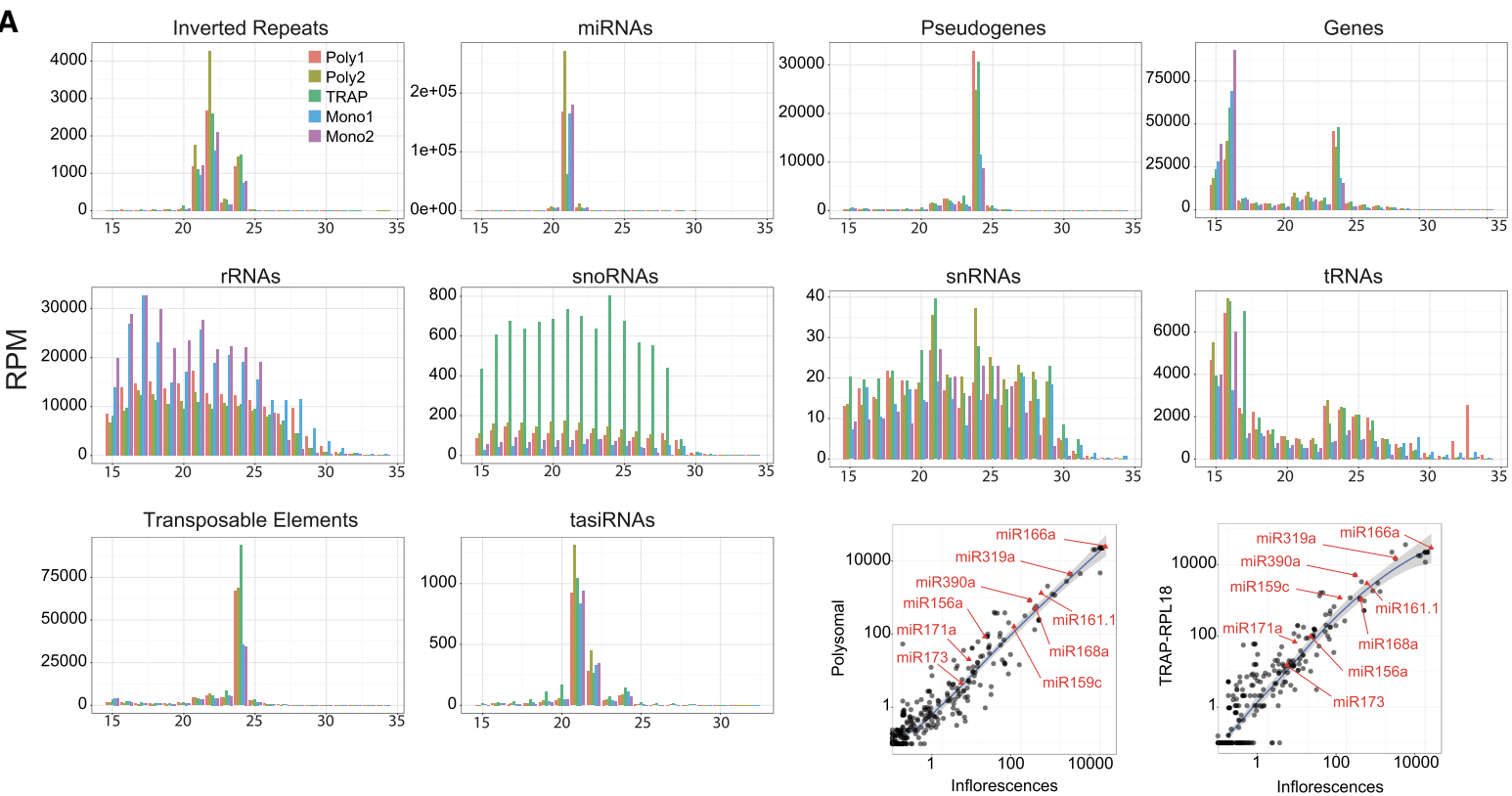

B

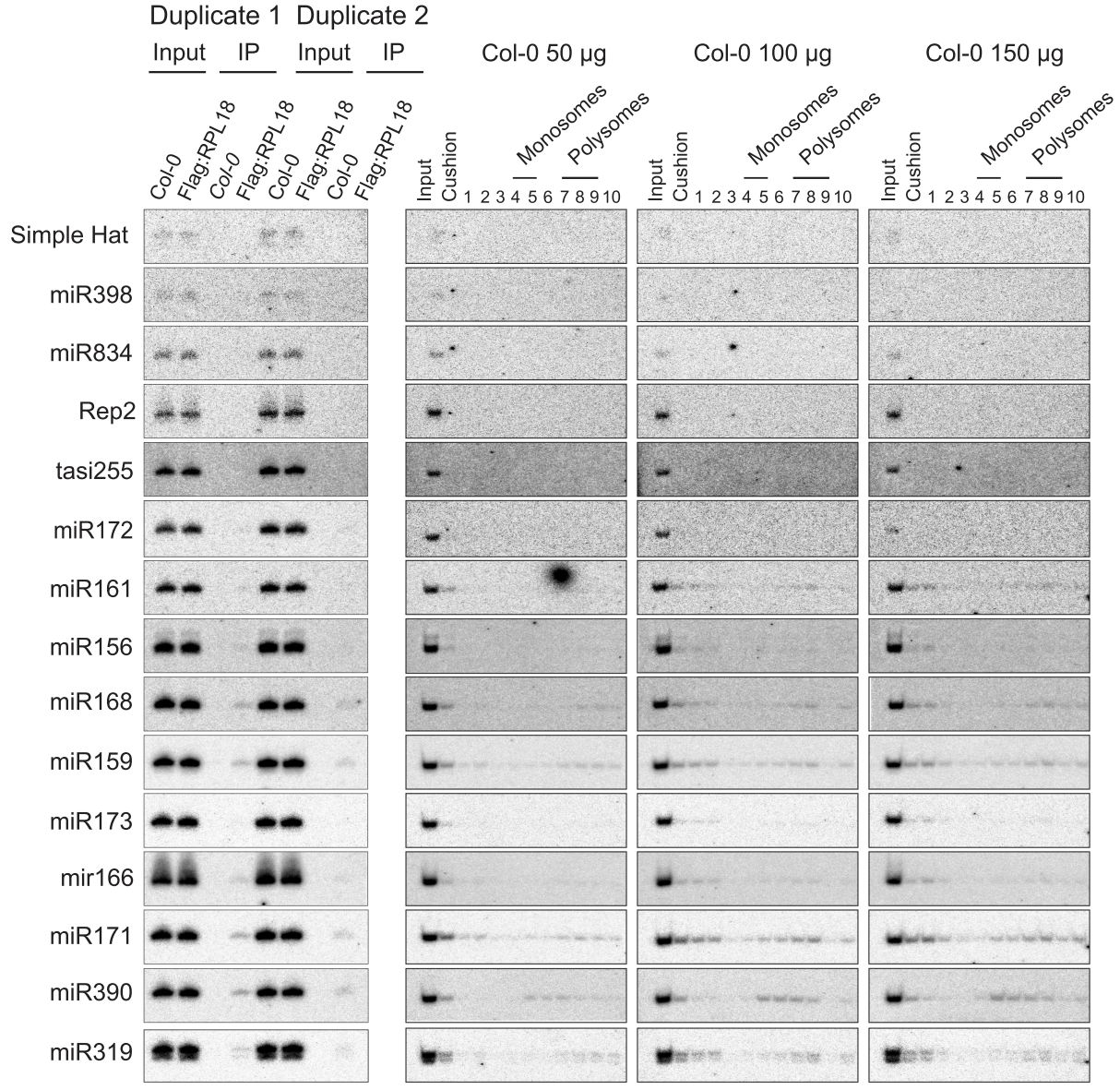

FIGURE 2. miRNA steady-state levels correlate with their association with polysomes. (A) Read size distribution in reads per million (RPM) grouped by genomic annotation for monosomal (Mono1 and Mono2), polysomal (Poly1 and Poly2), and TRAP sRNA-sequencing libraries. Correlations between mature miRNA accumulations in polysomal fraction versus inflorescences and TRAP versus inflorescences are shown in the lower right corner, with selected miRNAs indicated in red. (B) TRAP and RP were conducted in parallel as in Figure 1A,B to monitor the abundance of tasi-, mi- and siRNAs in ribosomal complexes via northern analysis using labeled complementary oligonucleotide or random-primed PCR-amplified fragments as probes, respectively. For RP, varying inputs of total RNA, as indicated, were loaded onto the sucrose gradients. 
siRNAs were enriched similarly (Fig. 2A; Supplemental Fig. S3A). Both RP and TRAP methods thus revealed unexpectedly high levels of various 24-nt sRNAs associated with the translation machinery, and their consistent enrichment in total polysomes compared to monosomes.

\section{Polysomal association is not a miRNA-intrinsic property but a mere reflection of their steady-state accumulation levels}

With few exceptions, the deep-sequencing analyses revealed a strong correlation between total miRNA abundance and polysomal/TRAP association $\left(R^{2}=0.96\right.$ for both RPs and $R^{2}=0.86$ for TRAP; Fig. 2A, lower right corner). Hence, miR166a, miR319a, miR168a, miR390a, or miR159c, abundant in inflorescences and efficiently sequenced from both RP- and TRAP-isolated ribosomes, were also detected in separate northern analysis of sRNAs extracted via each method in biological duplicates and triplicates, respectively (Fig. 2B), confirming, incidentally, the reproducibility of the methods. miR172, in contrast, which is low in total inflorescences, had low read counts in poly1/poly2 and TRAP fractions and was below northern detection (Fig. 2B). However, some miRNAs below detection in TRAP-coupled northern analyses (e.g., miR161, miR156) became detectable in RP if the total amount of input RNA was increased to $100 \mu \mathrm{g}$ and beyond (Fig. 2B). miRNA polysomal association is, therefore, merely proportional to their steady-state levels, suggesting indeed that most, as opposed to select, miRNAs promote TR in addition to slicing (Brodersen et al. 2008), a conclusion also consistent with the findings of Li et al. (2016) in seedling-derived MBPs. This proportional relationship between total miRNA levels and polysomal association means that miRNAs not detected on total polysomes cannot be deemed as not mediating TR. Indeed, miR172, miR398, and miR834, three TR-promoting miRNAs (Chen 2004; Brodersen et al. 2008; Lanet et al. 2009; Li et al. 2013) eluded northern detection at up to $150 \mu \mathrm{g}$ of input RNA (Fig. 2B): these might be too low in abundance or accumulate only in specific cells of whole inflorescences. We also analyzed polysomal association of tasi/phasiRNA-trigger miRNAs (Felippes and Weigel 2009; Allen and Howell 2010; Vazquez et al. 2010), focusing on miR173 (TAS1/ TAS2) and miR390, (TAS3) accumulating respectively at low and high levels in inflorescences, since miR828, spawning TAS4-tasiRNAs, was at background levels in all samples. Underscoring the proportionality to steady-state levels evoked above, miR390 was readily detected and slightly enriched in polysomes versus monosomes in RP, and in TRAP versus total inflorescences (Fig. 2A, lower right corner), as confirmed by northern analyses. In contrast, miR173 was below detection at up to $150 \mu \mathrm{g}$ of input RNA (Fig. 2B); Li et al. (2016) found that miR173 is approximately twofold less abundant than miR390 in seedlingderived MBPs. While most phasiRNA-trigger miRNAs were at/below background in all libraries, miR472 (spawning phasiRNA from several CC-NBS-LRR transcripts) was consistently approximately twofold enriched in polysomes versus monosomes in RP, and in TRAP versus total inflorescences, despite its low steady-state levels. Perhaps the protein-coding nature of phasiRNA precursors enables a more sustained interaction of phasiRNA- compared to tasiRNA-trigger miRNAs with polysomes. Regardless, slicing is mandatory for most tasi/phasiRNA production, underscoring the coincidence of this process with TR, at least in whole-tissue analyses (Brodersen et al. 2008; Li et al. 2016).

\section{Endogenous siRNAs: tasiRNAs, IR-derived siRNAs, and 24-nt sRNAs}

Similar discrete peaks of $5^{\prime} U$ terminal 21-nt (and to a lower extent, of 24-nt species) miR173-dependent TAS1tasiRNAs were equally found in monosomes and polysome fractions, and in TRAP samples (Fig. 2A; Supplemental Fig. S4). The same was seen with TAS3-tasiRNAs, although the discrete D5(-) siRNA species produced from TAS3a was noticeably enriched in polysomes (Supplemental Fig. S4, asterisk). Thus, unlike miRNAs, AGO1-loaded tasiRNAs unlikely mediate trans-PTGS on polysomes but, rather, in distinct cytosolic locales possibly including the P-bodyproximal membranous structures involved in the unique RDR6-dependent dsRNA conversion of their precursors (Jouannet et al. 2012). Previous work had suggested that 21-nt siRNAs derived from an artificial IR transgene could mediate TR (Brodersen et al. 2008). Of eleven endogenous IRs identified in our laboratory, only IR71 and IR2039 (Henderson et al. 2006) showed above-background read counts among the sequencing libraries. Specific IR71-derived 22-nt, but not 24-nt, siRNAs were strongly polysome-enriched, corresponding to three discrete major species, of which two start with a $5^{\prime} \mathrm{U}$ and one with a $5^{\prime} \mathrm{C}$, the loading biases of AGO1 and AGO5 (Mi et al. 2008), respectively (Supplemental Fig. S4, asterisks); both IR2039derived 22-nt and 24-nt siRNA populations were globally enriched in total polysomal fractions (Supplemental Fig. S4). As mentioned, our survey revealed a significant enrichment of 24-nt sRNAs in total polysomes compared to monosomes, and their presence in TRAP samples was even more pronounced than that of 21-nt sRNAs (Fig. 2A; Supplemental Fig. S3A). This was unexpected since rasiRNAs, which form a large bulk of this sRNA size fraction, mediate RdDM in the nucleus (Feng and Jacobsen 2011; Law and Jacobsen 2010; Du et al. 2015; Matzke et al. 2015). Simple Hat-, si1003-, Rep2-, and AtSN1-derived rasiRNAs were effectively below detection in both RPand TRAP-coupled northern analyses and, accordingly, their polysome read counts in deep-seq analyses were respectively extremely low (si1003, Rep2, and Simple Hat) and low (ATSN1; Fig. 2B; Supplemental Fig. S3C). These 
observations may simply reflect the low steady-state levels of these and other individual rasiRNA specie. They may thus not be indicative of their lack of ribosome/polysome association per se, as discussed with some low-abundance miRNAs known to mediate TR (e.g., miR172). In fact, the presence of a large bulk of these molecules in total polysomes suggested the possible cofractionation of some 24-nt sRNA silencing effector protein(s) and indeed, 47\% of these species had a $5^{\prime} \mathrm{A}$ bias typical of AGO4-clade AGO cargoes (Supplemental Fig. S5).

\section{Ribosome profiling of distinct Arabidopsis AGO-clade members}

The above finding led us to examine if AGO4, or indeed other AGOs, associate with polysomes, in addition to AGO1. The ten Arabidopsis AGOs are divided into three phylogenetic clades (Morel et al. 2002; Vaucheret 2008; Mallory and Vaucheret 2011) of which several representatives were investigated here. The first "PTGS" clade comprises AGO1, AGO5, and AGO10 (Mi et al. 2008; Zhu et al. 2011). A second clade comprises AGO2, AGO3 and AGO7, mainly involved in antiviral silencing, seed development and miR390-directed tasiRNA biogenesis, respectively (Fahlgren et al. 2006; Montgomery et al. 2008; Carbonell et al. 2012; Pumplin and Voinnet 2013; Zhang et al. 2016). The third rasiRNA-associated "TGS" clade, encompasses AGO4, AGO6, AGO9 (Law and Jacobsen 2010; Feng and Jacobsen 2011; Du et al. 2015; Matzke et al. 2015); AGO8 is considered a pseudogene (Vaucheret 2008). In RP analysis, AGO2, AGO4, AGO5, and AGO10 were, like $A G O 1$, detected in polysomal fractions 7-9, but to varying extents (Fig. 3A). The presence of AGO5/ AGO10 was expected given their amino acid sequenceand functional-relatedness with AGO1 in mediating miRNA silencing in the shoot apical meristem (SAM; AGO10) and reproductive tissues (AGO5), respectively (Borges et al. 2011; Tucker et al. 2012; Roodbarkelari et al. 2015; Zhou et al. 2015). AGO2, member of clade 2, was also readily detected on total polysomes, supporting recent evidence that besides its roles in antiviral defense (Jaubert et al. 2011; Scholthof et al. 2011; Zhang et al. 2012), AGO2 regulates mRNA translation (Fátyol et al. 2016) including, possibly, via stress-induced miRNA cargoes (Zhang et al. 2011). Both AGO4 and AGO9 were strongly detected in the light fractions $1-2$, possibly because both are parts of large RdDM nuclear complexes (Law and Jacobsen 2010; Feng and Jacobsen 2011; Du et al. 2015; Matzke et al. 2015) that might pass through the sucrose cushion and reach the first two gradient layers (Fig. 3A, fractions 1-2). Strikingly, however, AGO4 also consistently cosedimented with polysomal fractions 7-9, albeit at comparably lower levels than in fractions $1-2$. In their recent analysis, $\mathrm{Li}$ et al. (2016) could not detect AGO4 in seedling's microsomal fractions or MBPs, unlike
AGO1. These observations suggest that $\mathrm{AGO} 4$ in fractions 7-9 is one source of polysomal 24-nt sRNAs detected by RP and observed in TRAP, and that this AGO4 pool exerts as yet unidentified function(s) distinct from miRNA-mediated silencing on the ER, or PTGS mediated by AGO1 on other endo-membranes (Fig. 3A, fractions 7-9). Despite repeated attempts, we failed to detect silencing effectors other than AGO1 in the TRAP immunoprecipitated fractions.

\section{Polysome-associated 24 nt siRNAs with a $5^{\prime}$ terminal cytosine bias are overrepresented in AGO5 immuno- precipitates, map to pseudogenes and are more sequenced in siliques}

More than half of annotated ribosome-associated 24-nt sRNAs detected by TRAP or RP map to protein-coding genes and pseudogenes, but not TEs/repeats, and thus do not qualify as bona fide rasiRNAs (Fig. 2A; Supplemental Fig. S3A). As already discussed, individual TEs/repeats usually spawn, on their own, only low levels of 24-nt rasiRNAs contributing however, as a whole, the largest bulk of Arabidopsis silencing sRNAs due to the repeated nature of their loci-of-origin. Genes define unique loci and, therefore, the sheer quantity of 24-nt sRNAs spawned from them (Fig. 2A; Supplemental Fig. S3A) suggests that at least some genes individually generate large amounts of these molecules. Indeed, 20 loci accounted, alone, for nearly half of the protein-coding gene-mapping 24-nt unique reads in inflorescences (five examples are presented in Supplemental Fig. S6; Supplemental Table 1 lists all examples). Inspection of a further 80 genes (thus, 100 genes in total) showed that, in most cases, 24-nt sRNA populations as opposed to discrete species, were derived from them, with very few overlapping 21-nt and 22-nt sRNA species, if at all (Supplemental Table 1). Of these 100 genes, $79 \%$ are located $<1 \mathrm{~kb}$ from TEs or remnants thereof, compared to $39.3 \%$ for the entire Arabidopsis gene-set (Supplemental Fig. S7). The Helitron superfamily represented $67.9 \%$ of TEs found in the vicinity of unique 24-nt sRNA-producing loci compared to the $46.4 \%$ of TEs nearby the entire Arabidopsis gene-set. The small nonautonomous AtRep10D, which produces large quantities of 24-nt siRNAs, represented, alone, $13.5 \%$ of these compared to $5.3 \%$ for the whole Arabidopsis gene-set. Strikingly, however, in the majority of cases, the protein-coding gene-proximal TEs did not spawn themselves the 24-nt sRNA populations. These mapped, instead, within the coding regions and, to a lower extent, introns (Supplemental Fig. S6; Supplemental Fig. S8A, B) and correlated with cytosine methylation patterns almost exclusively in the $\mathrm{CHG}$ and $\mathrm{CG}$ contexts indicating maintenance methylation (Supplemental Fig. S8C, compared with $3 \mathrm{D}$ cluster 2). These observations agree with a key role for CHROMOMETHYLASE 3 (required for CHG methylation maintenance) in gene body methylation (gbM) and with a speculated TE-silencing-related origin 

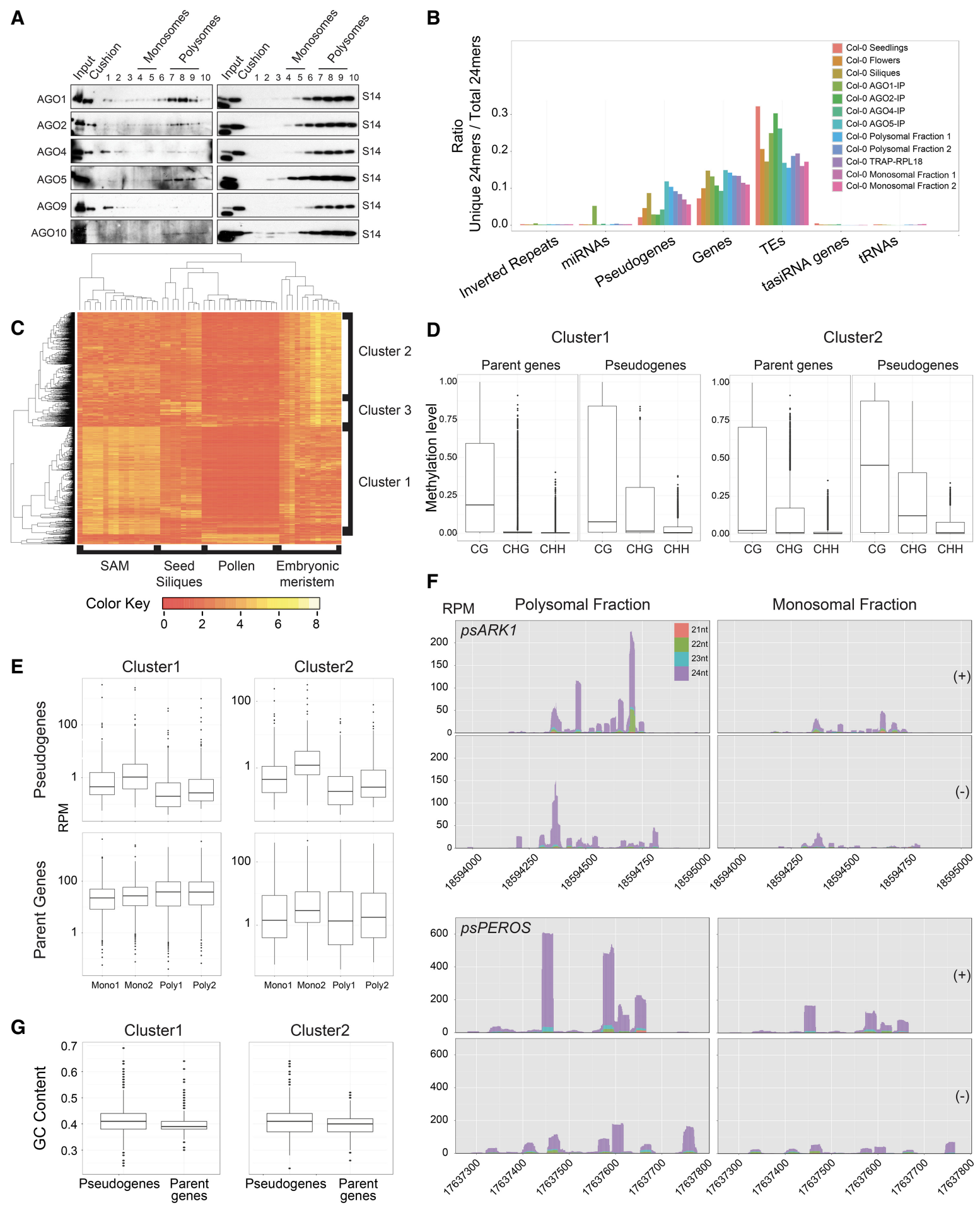

FIGURE 3. In silico identification of pseudogene derived siRNAs. (A) Western analysis of AGO1, AGO2, AGO4, AGO5, and AGO10 upon cosedimentation on monosomes and polysomes via RP, as in Figure 1B. The ribosomal protein S14 was used as a control to verify the RP quality. This experiment was produced in triplicate. (B) Ratios of unique-mapper 24-nt siRNAs versus total 24-nt siRNAs, grouped by genomic annotation of sRNAs from publicly available sequencing libraries of total RNA and AGO IPs. (C) Expression heat-map of pseudogene derived siRNA parent genes at the various developmental stages encompassed in the bar.toronto database, using unsupervised hierarchical clustering. (D) Boxplot representation of average cytosine methylation levels in the three contexts for parent genes and respective pseudogenes of cluster 1 or cluster 2. (E) mRNA steady-state accumulation in polysomal and monosomal fractions based on RNA-seq conducted in the indicated libraries, for the parent genes and respective pseudogenes of cluster 1 or cluster 2. $(F)$ Total 21-to-24 nt sRNA accumulation profiles for psARK1 and psPEROS pseudogenes, in polysomal and monosomal fractions. $(G)$ Boxplots representation of average GC contents for parent genes and respective pseudogenes in cluster 1 or cluster 2 . 
of this otherwise poorly understood phenomenon (for review, see Bewick and Schmitz 2017).

Next, we focused on 24-nt sRNAs derived from pseudogenes, reannotated in the present study in order to encompass the largest set of loci (Supplemental Table 3). To do so, we implemented a bidirectional hit strategy using blastx and tblastn to detect shared homology between intergenic regions and protein-coding genes (see Materials and Methods). Because some pseudogene sequences may be repeated, including as a consequence of TE-driven reverse-transcription, we distinguished total 24-nt siRNAs (including the major rasiRNA fraction from TEs and repeats) from the 24-nt sRNAs specifically derived from pseudogenes and genes, and, finally, the 24-nt sRNA reads mapping to unique genomic regions (termed "unique mappers" thereafter) encompassing almost exclusively genes and pseudogenes. Interestingly, gene- and pseudogene-derived 24-nt sRNAs were enriched by 1.9- and 3.1-fold in TRAP and polysome fractions, respectively, compared to monosomes (Fig. 2A). Furthermore, pseudogene-derived 24-nt unique mappers were 2.6 times more abundant in polysomes and TRAP, than in monosome fractions (Supplemental Fig. S3D). This enrichment was not an artifact of pseudogene reannotation, because it was similarly observed using the TAIR-based annotation (Supplemental Fig. S3E). The (24-nt unique mappers to total 24-nt siRNAs) ratio, calculated for each genomic annotation, also revealed an enrichment in 24-nt unique mappers for sRNAs derived from pseudogenes and, to a lesser extent, genes, in the polysome- and TRAP-, compared to monosomes- and total inflorescence-libraries (Fig. 3B). We investigated if the 24-nt unique mappers displayed preferential loading into AGO protein(s) using the publicly available data set of Mi et al. (2008), which provides a comparative sRNA analysis of AGO1, AGO2, AGO4, and AGO5 immunoprecipitates (IPs; Fig. 3B). Strikingly, the AGO5 IP library showed the highest enrichment in unique pseudogene-derived $24 \mathrm{nt}$ sRNAs. These were respectively $2.5-$ and 2.9-fold higher than in total inflorescences and AGO4 IPs (Fig. 3B). 91\% of pseudogene-derived $24 \mathrm{nt}$ sRNAs loaded into AGO5 displayed the cognate $5^{\prime} \mathrm{C}$ signature of its cargoes (Mi et al. 2008). Their genomic origin, unique-mapper properties, occurrence as sRNA populations and hitherto unknown enrichment in $\mathrm{AGO} 5$ and on polysomes, suggest that pseudogene 24-nt sRNAs should now be inspected as a novel class of plant siRNAs. siRNAs exhibiting unique mapping mostly in intergenic regions and, in some cases, loaded into AGO5 were described in maize and rice as meiotic $24 \mathrm{nt}$ and premeiotic 21/22 nt phasiRNAs (Komiya et al. 2014; Zhai et al. 2015). Mining total sRNA-seq data from various tissues/developmental stage revealed that pseudogene derived siRNAs are enriched in siliques where they are 1.9-fold more abundant than in total inflorescences (Fig. 3B). In polysomes, siliques and AGO5-IP libraries the (unique mappers to total 24-nt
siRNAs) ratio from pseudogenes even reaches quantitatively that from TEs/repeats, i.e., 11.8\% in AGO5-IP, 9.7\% in polysomal fractions and $8.7 \%$ in siliques (Fig. 3B).

Many pseudogenes are spawned from expressed genes often encoding functional proteins, called "parent genes" (Xiao et al. 2016). Therefore, pseudogene derived siRNAs could interfere with their corresponding "parent genes" expression analogously to pseudogene-derived siRNA in the distant protozoan Tryposonoma brucei (Wen et al. 2011). Hierarchical clustering based on the bar.utoronto gene expression atlas (http://bar.utoronto.ca/ dev/ eplant/) uncovered highly specific pseudogene parent gene expression patterns, which can be divided into three main clusters (Fig. 3C). Cluster 1 includes parent genes globally down-regulated in the pollen and up-regulated in the SAM, whereas parent genes from cluster 2 are also down-regulated in the pollen but mainly up-regulated in the embryonic meristem. Parent genes from the much smaller cluster 3 follow a similar expression pattern to those of Cluster 2 but with a higher expression in siliques. These specific expression profiles suggest that, within each cluster, parent genes and/or pseudogene derived siRNA-producing loci are under selection. Analyses of the parent genes and pseudogenes distribution for cluster 1 and 2 showed that they are equally represented on the five Arabidopsis chromosomes. (Supplemental Fig. S3F). However, while cluster 1 parent genes are, overall, homogeneously distributed along the chromosomes' arms only, their related pseudogenes are also present, even enriched, in peri-centromeric regions, giving rise to strikingly mutually exclusive distribution patterns in these regions (Supplemental Fig. S3F). In contrast, both pseudogenes and parent genes from cluster 2 show a similar distribution more concentrated on peri-centromeric regions (Supplemental Fig. S3F). Like pseudogenes of both cluster 1 and 2 , the presence of cluster 2 parent genes into peri-centromeric regions likely entails transposition events, and indeed a search for close-proximity TEs $(<1 \mathrm{~kb})$ revealed a significant (Fisher-test: $P$-value $<1 \times 10^{-16}$ ) TE enrichment in the vicinity of cluster 2 compared to cluster 1 parent genes (Supplemental Fig. S9) and was likely underestimated given that ancient TE excision sites are difficult to detect, as are degenerated TEs.

Due to their high TE/repeat content, peri-centromeric regions are heavily DNA methylated, heterochromatic and predominantly transcriptionally silenced. Thus, the specific combinations of pseudogene/gene distribution within cluster 1 and 2 might partially explain the distinctive expression patterns displayed in Figure $3 \mathrm{C}$ as a result of contrasted epigenetic regulations (Lippman et al. 2004). Agreeing with this idea, mining the whole-genome bisulfite sequencing data produced by Stroud et al. (2013) revealed that both parent genes and pseudogenes from cluster 2 display cytosine methylation in the CG (high), $\mathrm{CHG}$ (moderate) and $\mathrm{CHH}$ (low) context, a result consistent 
with the more peri-centromeric localization of both types of loci and the involvement of RdDM (Fig. 3D). Although epigenetic reprograming would likely enable their expression at specific developmental (including chiefly, reproductive) stages (Klosinska et al. 2016; Martinez and Köhler 2017), parent- and pseudo-genes of cluster 2 are thus predicted to be poorly expressed and/or translated, on average. Indeed, transcripts from both types of cluster 2 loci were equally poorly represented in RNA-seq libraries of the two separate monosomes and polysome fractions prepared by RP in this study (Fig. 3E). While pseudogenes of cluster 1 display a methylation pattern similar in extent and nature to that of parent genes/pseudogenes of cluster 2, DNA methylation in CHG and CHH contexts is nearly absent from cluster 1 parent genes, which display, however, CG methylation but at significantly lower levels than in cluster 1 pseudogenes and cluster 2 genes/pseudogenes. This specific pattern presumably reflects the preferential euchromatic location, transcription and mRNA translation of cluster 1 genes (Fig. 3D). Indeed, while cluster 1 pseudogene transcripts were as poorly represented on monosomes/polysomes as their cluster 2 counterparts, those of cluster 1 parent genes were 6.2-fold more abundant on ribosomes, with statistically higher levels on polysomes (Fig. 3E) (Fisher-test: $P$-value $<1 \times 10^{-16}$ ).

Figure 3F provides examples of siRNAs mapped onto two pseudogenes from cluster 1, of which the corresponding parent genes will be analyzed in a further section of this study. As seen with protein-coding gene-derived 24 nt unique mappers (Supplemental Fig. S6), pseudogene derived siRNAs are enriched in the polysomal as opposed to monosomal fractions suggesting their involvement in translation regulation downstream the initiation step. One feature that might predispose polysomal pseudogene derived siRNAs to load into AGO5 by virtue of a $5^{\prime}-C$ terminal bias is an increase in GC content of siRNA-generating pseudogenes compared to parent genes, which is indeed clearly observed for cluster 1 and, as expected, to a lesser extent for cluster 2 pseudogenes (Fig. 3G).

\section{Genetics, AGO loading and developmental-stage specificity reveal two classes of cluster 1 pseudogene derived siRNAs}

Based on supervised classification by several features of polysome-associated 24 nt sRNAs (abundance in sRNAseq libraries, pseudogene-derived from small gene family with high sequence similarity), ten individual cluster 1 pseudogene derived siRNAs showing abundant reads in the deep-seq analyses were selected and manually curated for further studies (Supplemental Table 2). Given their apparent higher accumulation in these tissues, we first tried to detect these siRNAs by northern analysis of total RNA extracted from inflorescences of WT Arabidopsis or various mutant derivatives thereof. Out of ten random-primed PCR products corresponding to the genomic regions predicted to spawn each pseudogene derived siRNA population, six provided a clear signal including the four best computer-based predictions made with pseudogenes psARK1, psPEROS, psPROIN, and psPHR2 (Fig. 4A; Supplemental Fig. S10A,B; Supplemental Table 4). No significant variations in the levels of these six siRNA populations were observed in any of ten Arabidopsis ago single mutant backgrounds tested, nor were they altered in dc/4, rdr6 or rdr1 (Fig. 4A; Supplemental Fig. S10A,B). Pseudogene derived siRNAs were, however, below detection in hen 1, rdr2, poliv, but not polv mutants, indicating that their core biogenesis is similar to that of rasiRNAs spawned from pericentromeric regions (Fig. 4A; Supplemental Fig. S10A,B; Matzke and Mosher 2014; Wendte and Pikaard 2017). In dcl3 mutant plants, the pseudogene derived siRNAs accumulated as 22-nt sRNA species, while they were 21-nt in length in $d c / 2-d c / 3$ double mutants indicating the hierarchical involvement of DCL3 $\rightarrow$ DCL2 $\rightarrow$ DCL4 in their processing (Fig. 4A). Strikingly, psARK1, psPEROS and psPROIN siRNA levels were reduced or below detection levels in dcl1-11 suggesting that certain pseudogene derived siRNA precursors need first to be cleaved by DCL1 before being processed by DCL3, or that their biogenesis requires prior targeting of such precursors by miRNAs, as proposed for epigenetically activated siRNAs (easiRNAs) (Fig. 4A; Creasey et al. 2014).

Northern analysis of the six cluster 1 pseudogene derived siRNA populations during plant development and in various organs revealed that they are exclusively found in inflorescences and siliques, supporting a function during seed development (Fig. 4B). Among these candidates, siRNAs showed two inverted accumulation patterns in siliques, defining two classes. Class I, epitomized by psARK1-, psPEROS- and psPROIN-derived siRNAs accumulates mostly in 3-4 DAP siliques, whereas class II, represented by psPHR2, psMMDH1, and psNRBP2, predominates in closed flowers and >7DAP siliques (Fig. 4B; Supplemental Fig. S10C). We investigated the loading status of these populations in AGO1 and AGO4, because pseudogene derived siRNAs are composed of a minority of 21/22-nt and a majority of 24-nt sRNAs, as well as AGO5, because this protein is cytosolic, and specifically expressed in the pollen and siliques (Borges et al. 2011; Tucker et al. 2012; Roodbarkelari et al. 2015; Zhou et al. 2015). Although class II pseudogene derived siRNA populations exhibit an accumulation profile in inflorescences similar to several AGO4-loaded rasiRNAs including REP2 and SIMPLE HAT (Fig. 4B; Supplemental Fig. S10C), those derived from psPHR2 and psMMDH1 were below detection in AGO4 or indeed in other AGO IPs (Fig. 4C). Class I pseudogene derived siRNA populations including those derived from PsARK1, psPEROS and psPROIN, were loaded into $A G O 1, A G O 4$, and $A G O 5$ in inflorescences and 1-3 
A

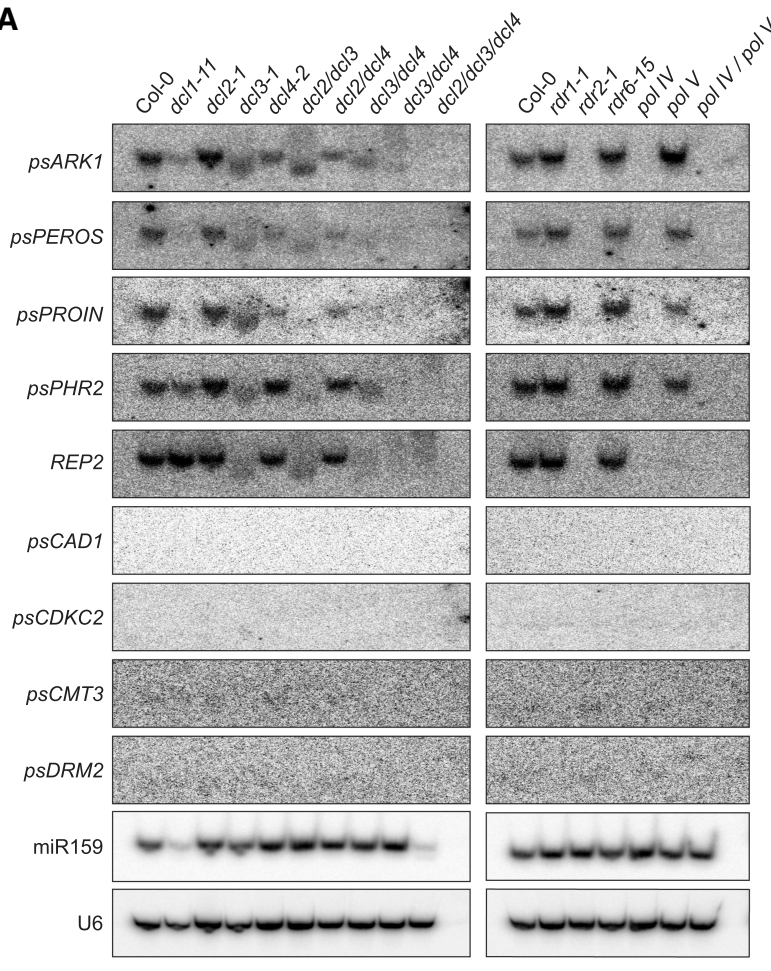

C

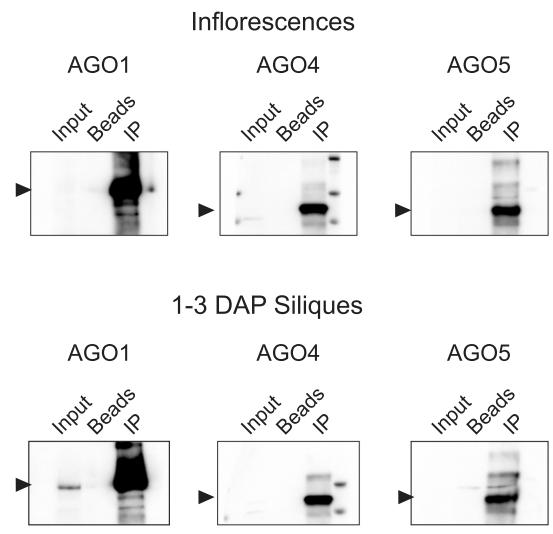

B
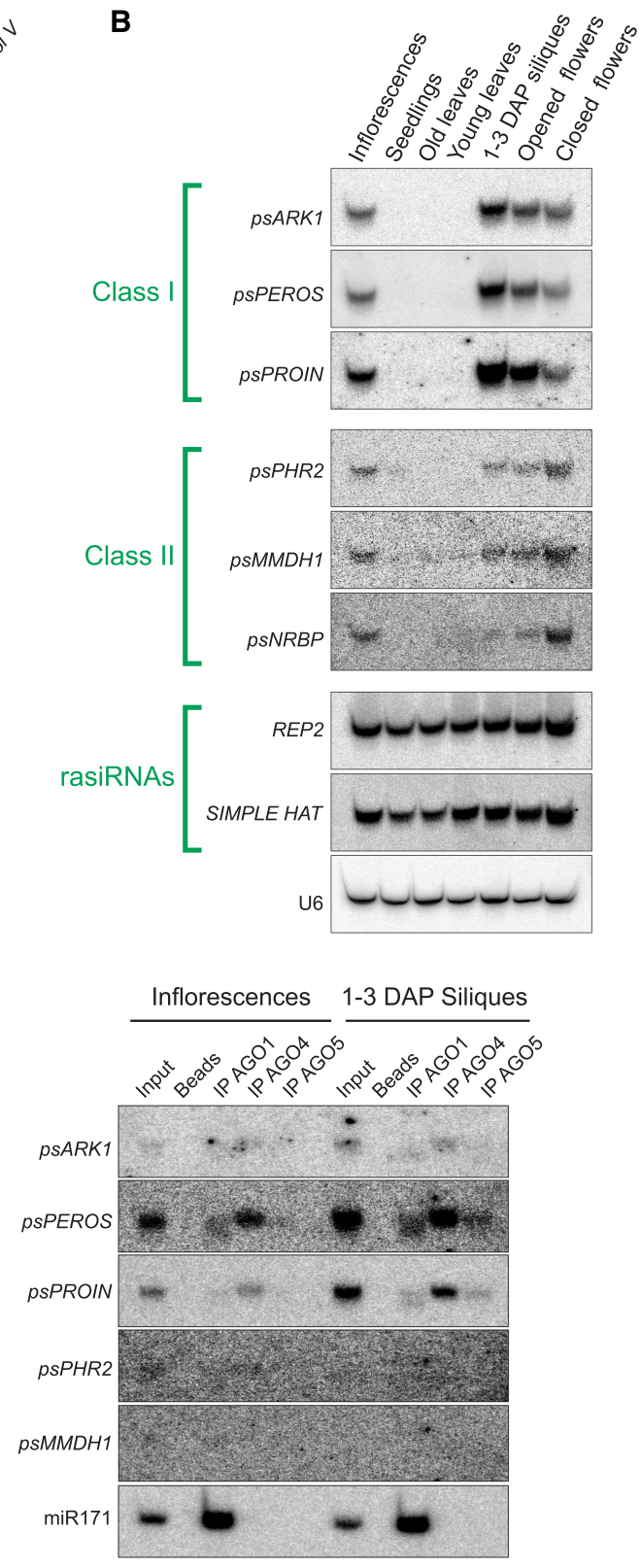

FIGURE 4. Tissue-specificities, biogenesis and loading of various pseudogene derived siRNA classes. (A) Northern analysis of specific pseudogene derived siRNA populations in the indicated genetic backgrounds from inflorescences; the hybridization probes were random-primed, PCRamplified DNA fragments covering the most abundant pseudogene derived siRNA signal detected in sRNAseQ analyses. (B) Same as in A but in various Arabidopsis tissues. sRNAs derived from REP2 and SIMPLE HAT were used as representatives of conventional rasiRNAs. (C) AGO1, AGO4, and AGO5 IPs were carried out from inflorescences and 1-3 DAP siliques, and the presence of the proteins in IP fractions was assessed by western analysis using antibodies against native proteins (left panel). Pseudogene derived siRNA populations co-IPed with the corresponding AGOs were detected by northern analysis as in $B$ (right panel). Hybridization to the U6 small RNA was used as a loading control in panels $A$ and $B$. $A$ and $B$ were produced in triplicate, $C$ in duplicate.

DAP siliques where they are most abundant (Fig. 4B,C), suggesting that class I siRNAs act at an early stage of seed development reminiscent of the epistatic interaction between AGO5 and chalcone synthase (CHS) siRNAs in glycine max (Cho et al. 2017). The 21-22-nt species from class I were loaded into AGO1 and AGO5, and the 24-nt species into $\mathrm{AGO} 4$ and $\mathrm{AGO} 5$ (Figs. 3B, 4C), respectively, suggesting that class I pseudogene derived siRNAs might mediate both PTGS, in trans, and RdDM in cis, most likely through a complex AGO proteins interplay. Supporting the former possibility, both AGO1 and AGO5 are cytosolic (Borges et al. 2011; Maldonado-Bonilla 2014), cosediment with polysomal complexes (Fig. 3A) and load 21-nt sRNAs, the molecules size usually associated with PTGS. However, 
we did not exclude that 24-nt pseudogene derived siRNAs loaded into AGO5 may also engage into this mode of RNA silencing, as explored in the next section.

\section{Class I, but not Class II pseudogene derived siRNAs of cluster 1 , are present on polysomes}

To further ascertain the existence of, and potential differences between, the two classes of cluster 1 pseudogene derived siRNAs, we conducted RP in whole inflorescences as well as 1DAP and 3DAP. To optimize signal detection and determine in which fraction(s) these siRNAs preferentially accumulate, light (1-2), monosomal (4-5), or polysomal (7-9) fractions were respectively grouped together and the coeluting sRNA subjected to northern analysis (Fig. 5). We found that class I, unlike class II pseudogene derived siRNAs cosediment with polysomes in a manner reflecting quantitatively their increasing abundance from inflorescences-to-3DAP siliques (Fig. 5). Accordingly, class $\mathrm{I}-$, but not class II-pseudogene derived siRNAs were also detected by deep-sequencing following TRAP: Both methods (RP an TRAP) showed a clear pseudogene derived siRNA enrichment dominated by $24-n t$ among rarer 21 -nt species (Figs. 2A, 3B). Together, these results suggest that class II pseudogene derived siRNAs are unlikely involved in translational regulations. We propose that they

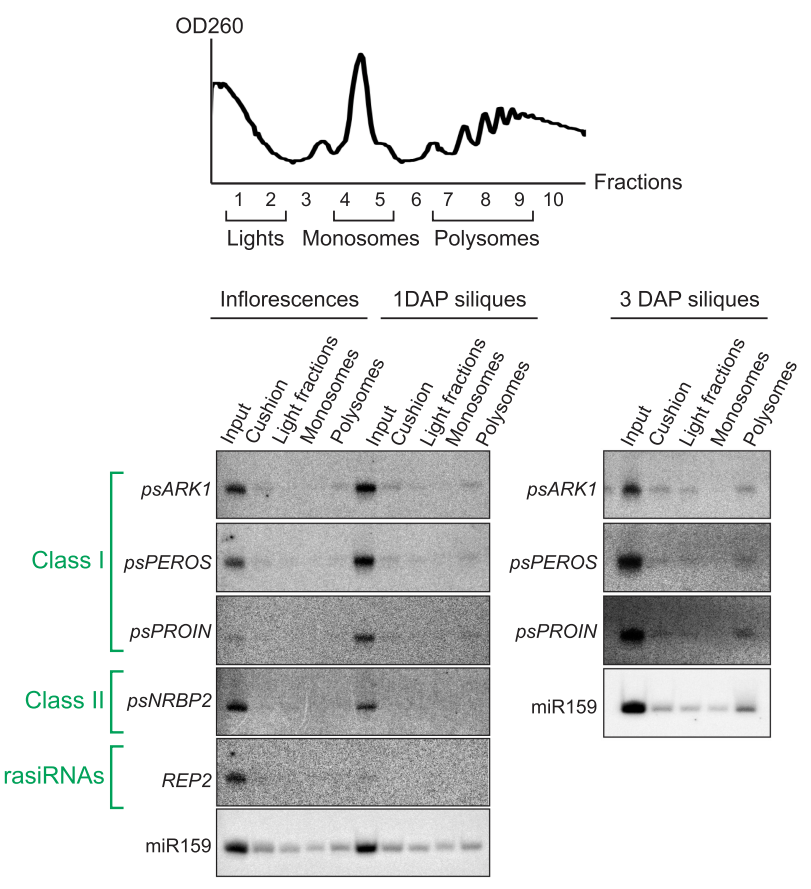

FIGURE 5. Class I, but not class II, pseudogene derived siRNAs cosediment in siliques' polysomes. RP conducted in inflorescences, 1DAP and 3 DAP siliques. Fractions 1 and 2 (light fractions), fractions 4 and 5 (monosomes), and fractions 7, 8, and 9 (polysomes) were pooled to optimize northern analysis of the indicated pseudogene derived siRNA populations as in Figure 4A. This experiment was produced in triplicate. probably mediate RdDM in an AGO4-dependent manner, agreeing with their accumulation profiles being similar to those of rasiRNAs (Fig. 4B; Supplemental Fig. S10C). In contrast, class I pseudogene derived siRNAs, including their 24-nt forms, interact with the translation machinery via AGO5 alongside, possibly, AGO4 (Fig. 4C). Northern analysis of predicted parent genes' transcripts from selected class I pseudogene derived siRNAs showed that their levels were not significantly changed in the $r d r 2$ and $d c / 3$ backgrounds-which alleviate pseudogene derived siRNA production altogether (Fig. 4A) - and in various plant tissues showing strong fluctuation in pseudogene derived siRNA levels (Fig. 4B; Supplemental Fig. S10C). These results, confirmed by semiquantitative RT-PCR analysis and high molecular northern blots (Supplemental Fig. S11), are consistent with the idea that class I pseudogene derived siRNAs possibly modulate target gene expression translationally.

\section{DISCUSSION}

Work presented here constitutes, thus far, the most exhaustive and unbiased analysis of the silencing sRNA cohorts and AGO effector proteins associated with the translational apparatus of Arabidopsis. Although they rely on completely unrelated biochemistry, both the TRAP and RP approaches provided largely mutually consolidating results such that the corresponding sRNA-seq data sets generated in inflorescences should become a solid and valuable resource to the plant community. The specific analysis of miRNA/AGO1 association with total polysomes consolidates and extends further the conclusions drawn from the pioneering study conducted by $\mathrm{Li}$ et al. (2013) on seedling-derived MBPs. It can now be safely stated that most, unlike a select category of plant miRNAs, have the potential to mediate TR because they associate on polysomes with target mRNAs as part of AGO1-, and as suggested here, AGO5-, AGO10- and perhaps AGO2-RISCs. In the case of AGO1-RISCs, this association occurs in an AMP1-dependent manner and at levels reflecting the mere cellular steady-state accumulation of miRNAs in the tissues/growth stages analyzed (e.g., seedlings, inflorescences). Both studies raise, however, the long-standing, unsolved and yet fundamental issue of how slicing and TR might be concurrently achieved on polysomes/MBPs? One possibility entails that slicing (anticipated to rely on AGO1 without associated proteins), despite its multiturnover nature, might never be complete and/or that excessive mRNA levels might be rate-limiting for this reaction. For any given miRNA, a varying pool of unsliced target mRNA would thus remain sufficiently available on polysomes to allow assembly of a putative AGO1associated protein complex required for TR. This complex might comprise the GW-repeat-containing protein SUO (Yang et al. 2012), which, as seen with the metazoan 
GW182, may facilitate miRNA translational repression by recruiting the CCR4-NOT deadenylase complex to target mRNAs (Rogers and Chen 2013). Alternatively, TR and slicing in plants may be physically separated phenomena occurring in distinct cell types in a manner that cannot be adequately resolved by analyzing whole tissues or organs, which form complex cell mosaics (Voinnet 2009). The latter was recently supported by a study conducted at singlecell-type resolution in the Arabidopsis root tip (Brosnan et al. 2019).

One aspect consistently evidenced by both RP and TRAP approaches is the surprisingly small amount of cellular AGO1 available to miRNA action on polysomes. Since miRNAs represent, by far, the main AGO1 cargoes in healthy Arabidopsis, the observation suggests that the steady-state association of the AGO1:miRNA complex to target transcripts is low, and that, consequently, the largest pool of this complex is found elsewhere in the cell or occupied by another mechanism. Up to now, miRNA loading into AGO1 has been inferred to occur in the cytosol despite little, if any, supporting experimental evidence. If, as suggested by cell biology (Fang and Spector 2007), mechanistic data (Eamens et al. 2009), and their stepwise nuclear maturation (Voinnet 2009; Rogers and Chen 2013), loading of plant miRNAs into AGO1 precedes their export to the cytosol, it would be anticipated that a large AGO1 pool would be engaged into nucleo-cytosolic shuttling. We have indeed recently provided evidence that AGO1 displays such a property and loads mature miRNAs in the nucleus, from which AGO1:miRNA complexes are then exported in a CRM1-dependent manner (Bologna et al. 2018). Besides, we found that the modest AGO1 pool able to bind polysomes still does so in the hen 1 mutant. We tentatively attributed this effect to the residual miRNAs found in hen 1 although Li et al. (2016) reported that AGO1 still binds polysomes in the miRNA-deficient hyl1 and dcl1 mutants. The same authors also suggested that lack of siRNAs does not affect AGO1 association to polysomes. This apparent inconsistency could perhaps be solved by studying a miRNA-binding deficient AGO1 allele, if viable.

Our work in inflorescences revealed unexpectedly large amounts of 24-nt sRNAs associated with total monosomes and, even more so, on polysomes. These were not found by Li et al. (2016) on seedling-derived MBPs, suggesting that the polysome-associated 24-nt siRNAs might be selectively enriched in non-MBP. Approximately half of these molecules correspond to multimappers derived from TEs and repeats and thus represent bona fide rasiRNAs which could therefore possibly mediate PTGS and TR via the previously unknown polysomal fraction of $\mathrm{AGO} 4$ identified here. TE-derived unique mapper 24-nt siRNAs, abundant in AGO1 and AGO2 (Fig. 3B), could also have this function. In all these circumstances, cytosolic rasiRNAs could act as a backup for RdDM, buffering potentially spurious Pol II transcription of otherwise epigenetically silent TEs via
Pol IV/V action. This speculative scenario is consistent with the unexplained prevailing cytosolic localization of rasiRNAs, and their loading into AGO4 in the cytosol before nuclear import (Ye et al. 2012). The second half of all polysome-associated 24-nt sRNAs is formed of unique mappers within large populations derived from the coding regions/introns of protein-coding genes, as well as from pseudogenes. Coding gene associated 24-nt sRNAs correlated with cytosine methylation patterns with the hallmarks of gbM. Although this process is found in 47 of 49 angiosperms investigated to date and although its varying extents among Arabidopsis ecological niches suggest an adaptive potential, no clear function has been attributed to $\mathrm{gbM}$ in modulating gene expression so far (Bewick and Schmitz 2017). However, all studies conducted to date have inferred effects at the mRNA and/or mRNA isoform level, but not protein production level. This stage of action might need to be considered in future investigations of gbM given the clear polysomal association of gene body-derived 24-nt sRNAs, and that a significant fraction of these species likely corresponds, in fact, to class Il pseudogene derived siRNAs of Cluster 1 (see below).

Thus far, pseudogene-derived 24-nt sRNA species have received little attention, if at all, and hence have been almost systematically categorized within a collective "rasiRNA-like" cohort of Arabidopsis sRNAs, yet the present study shows that this generic annotation requires amendment. Nonetheless, by no means does our study imply that pseudogenization, which may occur via a large variety of processes, necessarily entails sRNA production. Our study suggests a hitherto unknown and possibly prevalent function for AGO5 in mediating parent gene TR in inflorescences and siliques. According to our data, summarized in the speculative model in Figure 6, class I pseudogene derived siRNA and those from the major Cluster 1 in particular, which display transcriptionally and translationally active parent genes in chromosomal arms, but epigenetically silenced siRNA-generating loci near the centromeres, would be naturally predisposed to promote TR of their parent genes, via AGO5. Nonetheless, we do not exclude the contribution of other AGOs at this stage, including of AGO4, which also colocalizes with polysomes and strongly associates with pseudogene-derived siRNAs. Indeed, the degeneration process of pseudogenes is expected to naturally dilute the degree of complementarity between corresponding AGO5/4-loaded polysomal siRNAs, on the one hand, and the parent genes' transcripts, on the other. This would inherently favor translation repression over slicing due to sRNA/target sequence mismatches, particularly if these occur in the AGO catalytic core's vicinity (Supplemental Fig. S3G). The very tight developmental window of their production peaks in siliques and our failure to detect their predicted target proteins using commercial antibodies have so far prevented us to assess the presumed TR potential of these 


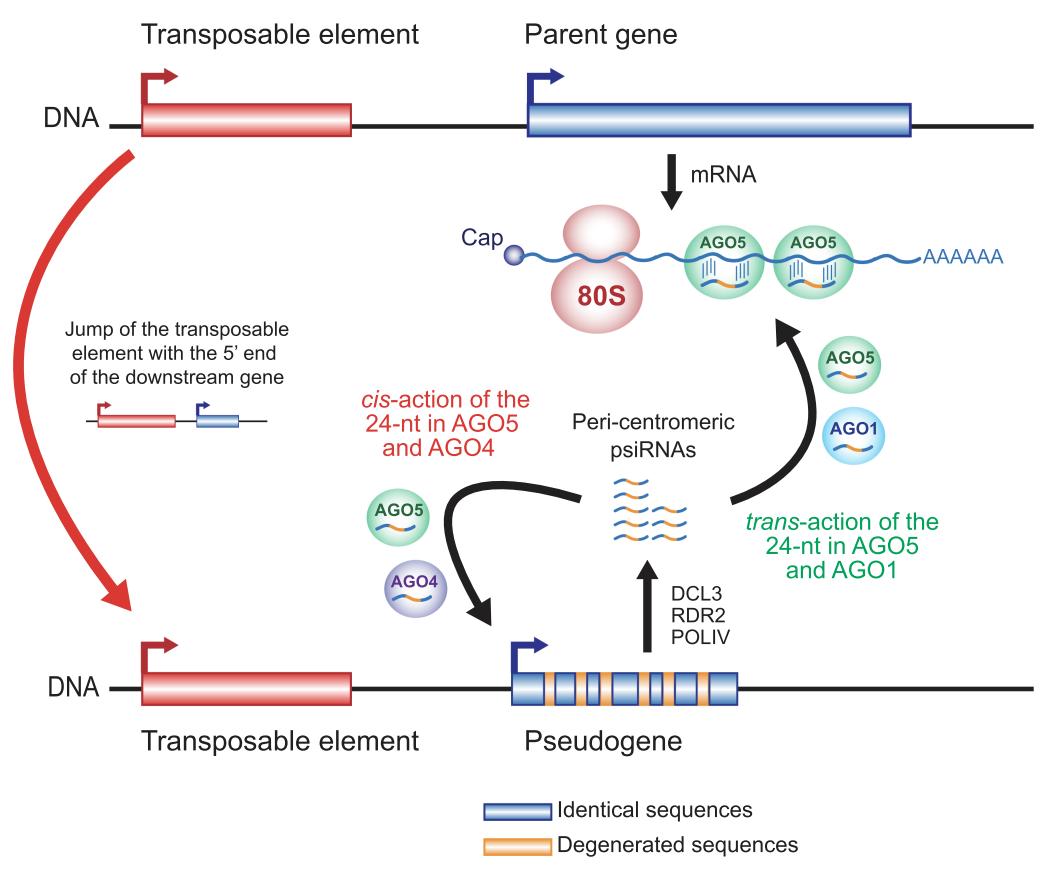

FIGURE 6. A model for the evolution and modes of action of Cluster 1 pseudogene derived siRNAs of class 1 .

pseudogene derived siRNAs. Use of adequately expressed mRNA sensors might help addressing this question, but even in this case, the likely cell-specificity and brief temporal accumulation of pseudogene derived siRNAs might require elaborated constructs based on short lived reporter proteins and gain-of-function rather than loss-of-function readouts. However, other evidences support this hypothesis. Premeiotic 21-nt phasiRNAs in maize and rice which exhibit pseudogene derived siRNA properties such as loading in cytosolic AGO5-related MEL1/AGO5c, tight spatiotemporal expression and unique mapping (Komiya et al. 2014; Zhai et al. 2015) are also unlikely to mediate cleavage of predicted targets as shown by PARE-sequencing data analysis, supporting an effect via AGO-directed TR activity and affinity for siRNAs with partial target complementarity. Partial target complementarity might also explain the poor $\mathrm{CHG}$ and $\mathrm{CHH}$ methylation pattern of cluster 1 parent genes if we assume Cluster 1 pseudogene derived siRNAs as mediator of de novo trans-methylation. In this TGS context, they would thus contribute mostly to (re)inforce cis-methylation onto the pseudogenes that spawn them.

It is also possible that pseudogene derived siRNAs act merely as buffers against inadequate/undesirable parent gene expression following developmental, stress or environmental cues, such that their regulatory output would be mostly invisible under ideal laboratory plant growth conditions. This scenario is attractive given that cluster 2 siRNA-generating loci are embedded into genomic regions replete with TEs, which are themselves potentially reactivated by stress, as well as AGO5 (Mirouze et al.
2009; Tsukahara et al. 2009; Ito et al. 2011; Brosseau and Moffett 2015). Noteworthy, many TEs are also epigenetically reactivated before and after fertilization (Lippman et al. 2004; Slotkin et al. 2009; Köhler and LafonPlacette 2015) the precise time window of pseudogene derived siRNA accumulation. A regulatory role for pseudogene derived siRNAs as modeled in Figure 6 in the case of class 1 siRNAs of cluster 1 could provide an interesting paradigm of coordinated, rather than independent, evolution of at least some pseudogene/gene pairs, similar in essence to the coevolution proposed for MIRNA genes and their target protein-coding loci, which indeed play the role of parent genes in at least one scenario of MIRNA birth (Cuperus et al. 2011). While addressing these and the many additional questions prompted by their discovery will require further extensive work, an immediately foreseeable application of pseudogene derived siRNAs is a refined annotation or, perhaps, redefinition, of plant pseudogenes, given the abundance of these molecules in inflorescences, unique mapper nature, and specific biochemical properties clearly setting them apart from conventional rasiRNAs.

\section{MATERIALS AND METHODS}

\section{Plant material}

Arabidopsis thaliana ecotype Columbia-0 (Col-0) was used in this study as wild type. All the mutant backgrounds have been previously described. (Burk et al. 2001; Chen et al. 2002; Morel et al. 2002; Peragine et al. 2004; Gasciolli et al. 2005; Xie et al. 2005; Bouché et al. 2006; Lobbes et al. 2006; Vaucheret 2008; Zhang et al. 2008; Jia et al. 2009; Lahmy et al. 2009; Mosher et al. 2009; Lam et al. 2012; Nagano et al. 2014)

\section{Plasmid construction and transformation}

35S:VSRs:HA constructs were generated using single-site Gateway technology (Invitrogen). VSRs were amplified with DNA primers (containing the gateway recombination sites B1 and B2, and the HA tag) using Phusion HF DNA Polymerase (Thermo Scientific) and cloned into pDONR 221 (Invitrogen). VSRs were mobilized by LR recombination into the $35 \mathrm{~S}$ promoter-containing vector PB7CWG2 (gateway vectors, Gent university) and the resulting constructs introduced into Agrobacterium tumefaciens GV3101. A. thaliana transformation was carried out by the floral dip method (Zhang et al. 2006). At least 
ten transgenic lines for each construct were analyzed in order to obtain at least one single-copy insertion line for each VSR.

\section{Ribosome profiling onto sucrose gradients}

Experiments were conducted according to the protocol of Mustroph et al. (2009). One gram of ground tissue was homogenized with $10 \mathrm{~mL}$ of PEB buffer $(200 \mathrm{mM}$ Tris- $\mathrm{HCl} \mathrm{pH}$ 9, 200 $\mathrm{mM} \mathrm{KCl}, 25 \mathrm{mM}$ EGTA, $36 \mathrm{mM} \mathrm{MgCl} 2,5 \mathrm{mM}$ dithiothreitol [DTT], $50 \mathrm{mg} / \mathrm{mL}$ cycloheximide, $50 \mathrm{mg} / \mathrm{mL}$ chloramphenicol, $1 \%[\mathrm{v} / \mathrm{v}]$ Triton X-100, 1\% [v/v] Tween 20, 1\% [w/v] Brij-35, 1\% $[\mathrm{v} / \mathrm{v}]$, Igepal CA-630, and $1 \%[\mathrm{v} / \mathrm{v}]$ polyoxyethylene). The crude extract was clarified by centrifugation at $3200 \mathrm{~g}$ for $10 \mathrm{~min}$ at $4^{\circ} \mathrm{C}$ and the supernatant loaded onto a $8 \mathrm{~mL}-1.6 \mathrm{M}$ sucrose cushion. After a high-speed centrifugation at $170,000 \mathrm{~g}$ for $3 \mathrm{~h}$ at $4^{\circ} \mathrm{C}$, pellets were resuspended in $400 \mu \mathrm{L}$ of wash buffer (200 mM Tris- $\mathrm{HCl} \mathrm{pH}$ 9, $200 \mathrm{mM} \mathrm{KCl}, 25 \mathrm{mM}$ EGTA, $36 \mathrm{mM}$ $\mathrm{MgCl}_{2}, 5 \mathrm{mM}$ DTT, $50 \mathrm{mg} / \mathrm{mL}$ cycloheximide, and $50 \mathrm{mg} / \mathrm{mL}$ chloramphenicol), and incubated $10 \mathrm{~min}$ at $4{ }^{\circ} \mathrm{C}$. Isolated ribosomal complexes were finally separated through 15\%-60\% $(\mathrm{v} / \mathrm{v})$ sucrose density gradients $(160,000 \mathrm{~g}, 2 \mathrm{~h})$ and 10 fractions of $700 \mu \mathrm{L}$ collected for further molecular analysis. Proteins were precipitated by addition of three volumes of ethanol absolute and pellets resuspended in $50 \mu \mathrm{L}$ of 2 X SDS-loading buffer for western analysis. RNAs were extracted by phenol/chloroform, and precipitated with three volumes of ethanol absolute. Pellets were resuspended in sterile water for analysis by northern blot or RNA deep sequencing.

\section{Immunoprecipitation of ribosome complexes}

Experiments were conducted using an established transgenic line (Arabidopsis Col-0) overexpressing the ribosomal protein RPL18 fused in amino-terminal with a $\mathrm{His}_{6}$-Flag tag (Zanetti et al. 2005). Briefly, $1 \mathrm{~g}$ of ground tissues was homogenized with $6 \mathrm{~mL}$ of PEB buffer (see above). The resulting lysate was clarified by centrifugation at $3200 \mathrm{~g}$ for $10 \mathrm{~min}$ at $4^{\circ} \mathrm{C}$, and precleared by incubation for 30 min with $15 \mu \mathrm{L}$ of protein A-agarose beads (Sigma). Beads were removed by centrifugation at $3200 \mathrm{~g}$ for $1 \mathrm{~min}$ and the clarified lysates incubated with $30 \mu \mathrm{L}$ of anti-Flag protein A-agarose beads (Sigma) for $3 \mathrm{~h}$ at $4^{\circ} \mathrm{C}$, on a rotating shaker. Beads were then washed four times with $6 \mathrm{~mL}$ of wash buffer (see above). Ribosomal complexes were finally resuspended in $70 \mu \mathrm{L}$ of wash buffer containing $1 \mathrm{mg} / \mathrm{mL} 3 x$ Flag peptide (Sigma) and eluted by incubation at $37^{\circ} \mathrm{C}$ for 30 min under strong agitation. As described for RP, proteins and RNAs were extracted from eluted complexes and further analyzed by western blot, northern blot, or RNA deep sequencing.

\section{RNA blot analysis}

For low-molecular-weight northern analysis, $10 \mu \mathrm{g}$ of total RNA was resolved on a denaturing $17.5 \%$ polyacrylamide-urea gel, electrotransferred to HyBond-NX membrane (GE Healthcare) and chemically crosslinked with 1-Ethyl-3-(3-dimethylaminopropyl)carbodiimide (EDC, Sigma). For high-molecular-weight northern analysis, $15 \mu \mathrm{g}$ of total RNA was resolved on denaturing $1.2 \%$ agarose gels with $2.2 \mathrm{M}$ formaldehyde, capillary transferred to the HyBond-NX membrane and chemically crosslinked with 1-Ethyl-3-(3-dimethylaminopropyl)carbodiimide (EDC, Sigma). DNA oligonucleotides complementary to microRNAs, tasiRNAs (tasiRNAs), rasiRNAs or U6 small nuclear RNA (snRNA) were $5^{\prime}$ end labeled with [ $\gamma$-32P]-dATP using T4 PNK (Thermo Scientific) (Supplemental Table 4). Radiolabeled PCR probes for the detection of pseudogene derived siRNAs and predicted pseudogene derived siRNA mRNA targets were made by random-priming reactions using the Prime-A-Gene kit (Promega) in the presence of $[\alpha-32 P]-d C T P$ (Hartmann Analytic) (Supplemental Table 4).

\section{Semiquantitative RT-PCR}

Accumulation of potential pseudogene derived siRNA targets in various plant tissues was measured by semi qRT-PCR using two independent pairs of gene-specific primers (Supplemental Table 4). Total RNA was extracted from A. thaliana with TRIzol (Invitrogen) and $2 \mu \mathrm{g}$ were reverse-transcribed into cDNA using the Maxima First-Strand cDNA Synthesis kit (Thermo Scientific). To control equal cDNA amounts in each reaction, a PCR was performed with primers corresponding to actin (AT3G18780).

\section{Protein blot analysis}

A total of 30-100 $\mu \mathrm{g}$ of proteins were resolved on SDS-PAGE, electrotransferred onto Inmobilon-P PVDF membrane (Millipore), and incubated with antibodies in PBST buffer (PBS, 0.1\% Tween-20, $5 \%$ nonfat dried milk). After incubation with HRP-conjugated secondary goat antibody to rabbit (Sigma), detection was performed with the ECL Western Blotting Detection kit (GE Healthcare). Affinity-purified antibodies were used at the indicated dilutions: AGO1 (1:5,000), AGO2 (1:3,000), AGO4 (1:5,000), AGO5 $(1: 3,000), \operatorname{AGO}(1: 5,000), \operatorname{AGO} 10(1: 3,000), \mathrm{S} 14(1: 10,000)$, and HA $(1: 5,000)$.

\section{AGO proteins immunoprecipitation}

Arabidopsis thaliana inflorescences and siliques were homogenized in $10 \mathrm{~mL}$ of IP buffer $(50 \mathrm{mM}$ Tris- $\mathrm{HCl}, \mathrm{pH} 7.5,150 \mathrm{mM}$ $\mathrm{NaCl}, 10 \%$ glycerol, $0.1 \% \mathrm{NP}-40$ ) containing $2 \mu \mathrm{M}$ proteasome inhibitor MG-132 and protease inhibitor cocktail (Complete). The resulting lysates were clarified by centrifugation at $3200 \mathrm{~g}$ for $10 \mathrm{~min}$ at $4^{\circ} \mathrm{C}$ and precleared by incubation on a rotating shaker with $15 \mu \mathrm{L}$ of Protein A-agarose beads (Sigma) for $30 \mathrm{~min}$ at $4^{\circ} \mathrm{C}$. Beads were removed by centrifugation at $3200 \mathrm{~g}$ for $1 \mathrm{~min}$. Clarified lysates were incubated with antibodies for $2 \mathrm{~h}$ at $4^{\circ} \mathrm{C}$ on a rotating shaker and for an additional $1 \mathrm{~h}$ with $15 \mu \mathrm{L}$ of Protein A-agarose beads. Beads were collected by centrifugation at $4000 \mathrm{~g}$, and washed three times with $1 \mathrm{~mL}$ of IP buffer. Immune complexes were finally resuspended in $70 \mu \mathrm{L}$ of wash buffer containing $1 \mathrm{mg} / \mathrm{mL}$ of AGO peptides (Agrisera and Eurogentec) and eluted at $37^{\circ} \mathrm{C}$ for 30 min under strong agitation. For RNA analysis, immune complexes were subjected to phenol/chloroform extraction. Aliquots of input, flow-through (before washes) and immunoprecipitated fractions were analyzed by western blot to assess the efficiency of immunoprecipitation. For immunoprecipitation of AGO1, AGO4, and AGO5 antibodies were used at a 1:1000 dilution. 


\section{Deep sequencing}

Five micrograms of total RNA were extracted from ribosome immunoprecipitation and RP by phenol/chloroform, processed into sequencing libraries using adapted Illumina protocols and sequenced at Fasteris (Geneva, Switzerland) using the HiSeq 2000 or 2500 sequencer. As prerequisite to small RNA-sequencing, gel size selection was performed to isolate 19-35 nt long RNA fragments. RNA-sequencing was performed from Total RNA in order to produce $2 \times 100$ bp paired-end, stranded reads.

\section{Bioinformatics}

All Arabidopsis genome annotations, except pseudogenes, inverted-repeats and miRNAs, were downloaded from the TAIR10 repository (arabidopsis.org). miRNA annotations were downloaded from miRbase v20. Mapping and annotation of RNA-sequencing libraries were computed with the Tophat v2.0.11 and Cufflinks v2.2.0 suites (Trapnell et al. 2009) with default parameters, except minimum intron size set to $60 \mathrm{nt}$ and maximum intron size to 5000 nt. sRNA libraries were mapped with the ncpro-seq tool v1.5.0 (Parameters: -e 50 -a -m 5000 -best -strata -nomaqround -y) (Chen et al. 2012). Annotation of inverted-repeats is not exhaustive and was compiled from current and previous work in the laboratory. To reannotate pseudogenes as summarized in Supplemental Figure S12, we first searched for shared homology between intergenic regions and protein-coding genes using Blastx ( $E$-value $\leq 1 \times 10^{-4}$ ). Then, we removed redundant alignments and merged, into contigs, overlapping sequences aligned against the same protein. To detect putative parent genes, we searched for shared homology querying Arabidopsis proteincoding genes against our contig database using tblastn (E-value $\leq 1 \times 10^{-4}$ ). As input, we used intergenic regions including the 929 already annotated pseudogenes and excluding transposons. As such, we defined 3738 pseudogenic regions corresponding to 2375 putative parent genes (Supplemental Table 3). 91\% of previously annotated pseudogenes were detected, the rest being composed of pseudogenes overlapping excessively with TEs. All the data were postprocessed using in-house shell and R scripts available upon request.

\section{Deep-sequencing data deposition}

The reproducibility and depth of the sRNA sequencing repeats produced for this work are summarized in Supplemental Figure S13. The publicly available deep-sequencing libraries used in the study, available on the Gene Expression Omnibus are GSE10036 series (AGO-IPs) (Mi et al. 2008), GSM1931307 (Siliques) (Pumplin et al. 2016), GSM1062223 (inflorescences) (Marí-Ordóñez et al. 2013). The following deep-sequencing data have been deposited on the Gene Expression Omnibus as follows: small-RNA deep-sequencing libraries from whole seedlings, TRAP, polysomal and monosomal fractions form the GSE99827 series (reviewer access with secure token: inadmcmojnorjcz). The RNA deep-sequencing libraries from polysomal and monosomal fractions (Fig. 3E) form the GSE99826 series (reviewer access with secure token: apatscoudpcrbul).

\section{SUPPLEMENTAL MATERIAL}

Supplemental material is available for this article.

\section{ACKNOWLEDGMENTS}

The authors thank the Voinnet laboratory for critical reading of the manuscript and in particular Alexis Sarazin and Emmanuel Devers. This work was supported by an advanced researcher grant from the European Research Council (ERC): grant number 323071, Frontiers of RNAi-II.

Received October 20, 2018; accepted April 7, 2019.

\section{REFERENCES}

Allen E, Howell MD. 2010. miRNAs in the biogenesis of trans-acting siRNAs in higher plants. Semin Cell Dev Biol 21: 798-804. doi:10.1016/j.semcdb.2010.03.008

Bewick AJ, Schmitz RJ. 2017. Gene body DNA methylation in plants. Curr Opin Plant Biol 36: 103-110. doi:10.1016/j.pbi.2016.12.007

Bologna NG, Iselin R, Abriata LA, Sarazin A, Pumplin N, Jay F, Grentzinger T, Dal Peraro M, Voinnet O. 2018. Nucleo-cytosolic shuttling of ARGONAUTE1 prompts a revised model of the plant microRNA pathway. Mol Cell 69: 709-719. doi:10.1016/j.molcel .2018.01.007

Borges F, Pereira PA, Slotkin RK, Martienssen RA, Becker JD. 2011. MicroRNA activity in the Arabidopsis male germline. J Exp Bot 62: 1611-1620. doi:10.1093/jxb/erq452

Bouché N, Lauressergues D, Gasciolli V, Vaucheret H. 2006. An antagonistic function for Arabidopsis DCL2 in development and a new function for DCL4 in generating viral siRNAs. EMBO J 25: 33473356. doi:10.1038/sj.emboj.7601217

Brodersen P, Sakvarelidze-Achard L, Bruun-Rasmussen M, Dunoyer P, Yamamoto YY, Sieburth L, Voinnet O. 2008. Widespread translational inhibition by plant miRNAs and siRNAs. Science 320: 1185-1190. doi:10.1126/science.1159151

Brodersen P, Sakvarelidze-Achard L, Schaller H, Khafif M, Schott G, Bendahmane A, Voinnet O. 2012. Isoprenoid biosynthesis is required for miRNA function and affects membrane association of ARGONAUTE 1 in Arabidopsis. Proc Natl Acad Sci 109: 17781783. doi:10.1073/pnas.1112500109

Brosnan CA, Sarazin A, Lim P, Bologna NG, Hirsch-Hoffmann M, Voinnet O. 2019. Genome-scale, single-cell-type resolution of microRNA activities within a whole plant organ. EMBO J 38: e100754. doi:10.15252/embj.2018100754

Brosseau C, Moffett P. 2015. Functional and genetic analysis identify a role for Arabidopsis ARGONAUTE5 in antiviral RNA silencing. Plant Cell 27: 1742-1754. doi:10.1105/tpc.15.00264

Burk DH, Liu B, Zhong R, Morrison WH, Ye ZH. 2001. A katanin-like protein regulates normal cell wall biosynthesis and cell elongation. Plant Cell 13: 807-827. doi:10.1105/tpc.13.4.807

Carbonell A, Fahlgren N, Garcia-Ruiz H, Gilbert KB, Montgomery TA, Nguyen T, Cuperus JT, Carrington JC. 2012. Functional analysis of three Arabidopsis ARGONAUTES using slicer-defective mutants. Plant Cell 24: 3613-3629. doi:10.1105/tpc.112.099945

Chen X. 2004. A microRNA as a translational repressor of APETALA2 in Arabidopsis flower development. Science 303: 2022-2025. doi:10.1126/science.1088060

Chen X, Liu J, Cheng Y, Jia D. 2002. HEN1 functions pleiotropically in Arabidopsis development and acts in $\mathrm{C}$ function in the flower. Development 129: 1085-1094. doi:10.1242/dev.00114 
Chen C-J, Servant N, Toedling J, Sarazin A, Marchais A, DuvernoisBerthet E, Cognat V, Colot V, Voinnet O, Heard E, et al. 2012. ncPRO-seq: a tool for annotation and profiling of ncRNAs in sRNA-seq data. Bioinformatics 28: 3147-3149. doi:10.1093/bioin formatics/bts587

Cho YB, Jones SI, Vodkin LO. 2017. Mutations in Argonaute5 illuminate epistatic interactions of the $K 1$ and $I$ loci leading to saddle seed color patterns in Glycine max. Plant Cell 29: 708-725. doi:10.1105/tpc.17.00162

Cognat V, Morelle G, Megel C, Lalande S, Molinier J, Vincent T, Small I, Duchêne A-M, Maréchal-Drouard L. 2016. The nuclear and organellar tRNA-derived RNA fragment population in Arabidopsis thaliana is highly dynamic. Nucleic Acids Res 45: 3460-3472. doi:10.1093/nar/gkw1122

Creasey KM, Zhai J, Borges F, Van Ex F, Regulski M, Meyers BC, Martienssen RA. 2014. miRNAs trigger widespread epigenetically activated siRNAs from transposons in Arabidopsis. Nature 508: 411-415. doi:10.1038/nature13069

Cuperus JT, Fahlgren N, Carrington JC. 2011. Evolution and functional diversification of MIRNA genes. Plant Cell 23: 431-442. doi:10 $.1105 /$ tpc. 110.082784

Del Prete MJ, Vernal R, Dolznig H, Mullner EW, Garcia-Sanz JA. 2007. Isolation of polysome-bound mRNA from solid tissues amenable for RT-PCR and profiling experiments. RNA 13: 414-421. doi:10 .1261/rna.79407

Derrien B, Baumberger N, Schepetilnikov M, Viotti C, De Cillia J, Ziegler-Graff V, Isono E, Schumacher K, Genschik P. 2012. Degradation of the antiviral component ARGONAUTE1 by the autophagy pathway. Proc Natl Acad Sci 109: 15942-15946. doi:10.1073/pnas.1209487109

Du J, Johnson LM, Jacobsen SE, Patel DJ. 2015. DNA methylation pathways and their crosstalk with histone methylation. Nat Rev Mol Cell Biol 16: 519-532. doi:10.1038/nrm4043

Eamens AL, Smith NA, Curtin SJ, Wang M-B, Waterhouse PM. 2009. The Arabidopsis thaliana double-stranded RNA binding protein DRB1 directs guide strand selection from microRNA duplexes. RNA 15: 2219-2235. doi:10.1261/rna.1646909

Fabian MR, Sonenberg N. 2012. The mechanics of miRNA-mediated gene silencing: a look under the hood of miRISC. Nat Struct Mol Biol 19: 586-593. doi:10.1038/nsmb.2296

Fahlgren N, Montgomery TA, Howell MD, Allen E, Dvorak SK, Alexander AL, Carrington JC. 2006. Regulation of AUXIN RESPONSE FACTOR3 by TAS3 ta-siRNA affects developmental timing and patterning in Arabidopsis. Curr Biol 16: 939-944. doi:10.1016/j.cub.2006.03.065

Fang Y, Spector DL. 2007. Identification of nuclear dicing bodies containing proteins for microRNA biogenesis in living Arabidopsis plants. Curr Biol 17: 818-823. doi:10.1016/j.cub.2007.04.005

Fátyol K, Ludman M, Burgyán J. 2016. Functional dissection of a plant Argonaute. Nucleic Acids Res 44: 1384-1397. doi:10.1093/nar/ gkv1371

Fei Q, Xia R, Meyers BC. 2013. Phased, secondary, small interfering RNAs in posttranscriptional regulatory networks. Plant Cell 25: 2400-2415. doi:10.1105/tpc.113.114652

Felippes FF, Weigel D. 2009. Triggering the formation of tasiRNAs in Arabidopsis thaliana: the role of microRNA miR173. EMBO Rep 10: 264-270. doi:10.1038/embor.2008.247

Feng S, Jacobsen SE. 2011. Epigenetic modifications in plants: an evolutionary perspective. Curr Opin Plant Biol 14: 179-186. doi:10.1016/j.pbi.2010.12.002

Gasciolli V, Mallory AC, Bartel DP, Vaucheret H. 2005. Partially redundant functions of Arabidopsis DICER-like enzymes and a role for DCL4 in producing trans-acting siRNAs. Curr Biol 15: 1494 1500. doi:10.1016/j.cub.2005.07.024
Gibbings DJ, Ciaudo C, Erhardt M, Voinnet O. 2009. Multivesicular bodies associate with components of miRNA effector complexes and modulate miRNA activity. Nat Cell Biol 11: 1143-1149. doi:10.1038/ncb1929

He X-J, Chen T, Zhu J-K. 2011. Regulation and function of DNA methylation in plants and animals. Cell Res 21: 442-465. doi:10.1038/cr .2011 .23

Henderson IR, Zhang X, Lu C, Johnson L, Meyers BC, Green PJ, Jacobsen SE. 2006. Dissecting Arabidopsis thaliana DICER function in small RNA processing, gene silencing and DNA methylation patterning. Nat Genet 38: 721-725. doi:10.1038/ng1804

Huntzinger E, Izaurralde E. 2011. Gene silencing by microRNAs: contributions of translational repression and mRNA decay. Nat Rev Genet 12: 99-110. doi:10.1038/nrg2936

Ito H, Gaubert H, Bucher E, Mirouze M, Vaillant I, Paszkowski J. 2011. An siRNA pathway prevents transgenerational retrotransposition in plants subjected to stress. Nature 472: 115-119. doi:10.1038/ nature09861

Jaubert M, Bhattacharjee S, Mello AFS, Perry KL, Moffett P. 2011. ARGONAUTE2 mediates RNA-silencing antiviral defenses against potato virus $X$ in Arabidopsis. Plant Physiol 156: 1556-1564. doi:10.1104/pp.111.178012

Jia Y, Lisch DR, Ohtsu K, Scanlon MJ, Nettleton D, Schnable PS. 2009. Loss of RNA-dependent RNA polymerase 2 (RDR2) function causes widespread and unexpected changes in the expression of transposons, genes, and 24-nt small RNAs. PLoS Genet 5: e1000737. doi:10.1371/journal.pgen.1000737

Jonas S, Izaurralde E. 2015. Towards a molecular understanding of microRNA-mediated gene silencing. Nat Rev Genet 16: 421433. doi:10.1038/nrg3965

Jouannet $V$, Moreno AB, Elmayan T, Vaucheret $H$, Crespi MD, Maizel A. 2012. Cytoplasmic Arabidopsis AGO7 accumulates in membrane-associated siRNA bodies and is required for ta-siRNA biogenesis. EMBO J 31: 1704-1713. doi:10.1038/emboj.2012.20

Juntawong P, Girke T, Bazin J, Bailey-Serres J. 2014. Translational dynamics revealed by genome-wide profiling of ribosome footprints in Arabidopsis. Proc Natl Acad Sci 111: E203-E212. doi:10.1073/ pnas. 1317811111

Juntawong P, Hummel M, Bazin J, Bailey-Serres J. 2015. Ribosome profiling: a tool for quantitative evaluation of dynamics in mRNA translation. Methods Mol Biol 1284: 139-173. doi:10.1007/9781-4939-2444-8_7

Kasschau KD, Fahlgren N, Chapman EJ, Sullivan CM, Cumbie JS, Givan SA, Carrington JC. 2007. Genome-wide profiling and analysis of Arabidopsis siRNAs. PLoS Biol 5: e57. doi:10.1371/journal .pbio.0050057

Klosinska M, Picard CL, Gehring M. 2016. Conserved imprinting associated with unique epigenetic signatures in the Arabidopsis genus. Nat Plants 2: 16145. doi:10.1038/nplants.2016.145

Köhler C, Lafon-Placette C. 2015. Evolution and function of epigenetic processes in the endosperm. Front Plant Sci 6: 130.

Komiya R, Ohyanagi H, Niihama M, Watanabe T, Nakano M, Kurata N, Nonomura K-I. 2014. Rice germline-specific Argonaute MEL1 protein binds to phasiRNAs generated from more than 700 lincRNAs. Plant J 78: 385-397. doi:10.1111/tpj.12483

Krol J, Loedige I, Filipowicz W. 2010. The widespread regulation of microRNA biogenesis, function and decay. Nat Rev Genet 11: 597-610. doi:10.1038/nrg2843

Lahmy S, Pontier D, Cavel E, Vega D, El-Shami M, Kanno T, Lagrange T. 2009. PolV(PollVb) function in RNA-directed DNA methylation requires the conserved active site and an additional plant-specific subunit. Proc Natl Acad Sci 106: 941-946. doi:10 .1073/pnas.0810310106

Lam P, Zhao L, McFarlane HE, Aiga M, Lam V, Hooker TS, Kunst L. 2012. RDR1 and SGS3, components of RNA-mediated gene 
silencing, are required for the regulation of cuticular wax biosynthesis in developing inflorescence stems of Arabidopsis. Plant Physiol 159: 1385-1395. doi:10.1104/pp.112.199646

Lanet E, Delannoy E, Sormani R, Floris M, Brodersen P, Crete P, Voinnet O, Robaglia C. 2009. Biochemical evidence for translational repression by Arabidopsis microRNAs. Plant Cell 21: 1762-1768. doi:10.1105/tpc.108.063412

Law JA, Jacobsen SE. 2010. Establishing, maintaining and modifying DNA methylation patterns in plants and animals. Nat Rev Genet 11: 204-220. doi:10.1038/nrg2719

Lee YS, Pressman S, Andress AP, Kim K, White JL, Cassidy JJ, Li X, Lubell K, Lim DH, Cho IS, et al. 2009. Silencing by small RNAs is linked to endosomal trafficking. Nat Cell Biol 11: 1150-1156. doi:10.1038/ncb1930

Lelandais-Brière C, Sorin C, Declerck M, Benslimane A, Crespi M, Hartmann C. 2010. Small RNA diversity in plants and its impact in development. Curr Genomics 11: 14-23. doi:10.2174/ 138920210790217918

Li S, Liu L, Zhuang X, Yu Y, Liu X, Cui X, Ji L, Pan Z, Cao X, Mo B, et al. 2013. MicroRNAs inhibit the translation of target mRNAs on the endoplasmic reticulum in Arabidopsis. Cell 153: 562-574. doi:10.1016/j.cell.2013.04.005

Li S, Le B, Ma X, Li S, You C, Yu Y, Zhang B, Liu L, Gao L, Shi T, et al. 2016. Biogenesis of phased siRNAs on membrane-bound polysomes in Arabidopsis. eLife 5: 120. doi:10.7554/eLife.22750

Lin SY, Chen PW, Chuang MH, Juntawong P, Bailey-Serres J, Jauh GY. 2014. Profiling of translatomes of in vivo-grown pollen tubes reveals genes with roles in micropylar guidance during pollination in Arabidopsis. Plant Cell 26: 602-618. doi:10.1105/tpc.113 .121335

Lippman Z, Gendrel A-V, Black M, Vaughn MW, Dedhia N, McCombie WR, Lavine K, Mittal V, May B, Kasschau KD, et al. 2004. Role of transposable elements in heterochromatin and epigenetic control. Nature 430: 471-476. doi:10.1038/nature02651

Lobbes D, Rallapalli G, Schmidt DD, Martin C, Clarke J. 2006. SERRATE: a new player on the plant microRNA scene. EMBO Rep 7: 1052-1058. doi:10.1038/sj.embor.7400806

Maldonado-Bonilla LD. 2014. Composition and function of P bodies in Arabidopsis thaliana. Front Plant Sci 5: 201. doi:10.3389/fpls .2014.00201

Mallory A, Vaucheret H. 2011. Form, function, and regulation of ARGONAUTE proteins. Plant Cell 22: 3879-3889. doi:10.1105/ tpc.110.080671

Marí-Ordóñez A, Marchais A, Etcheverry M, Martin A, Colot V, Voinnet O. 2013. Reconstructing de novo silencing of an active plant retrotransposon. Nat Genet 45: 1029-1039. doi:10.1038/ ng.2703

Maroney PA, Yu Y, Fisher J, Nilsen TW. 2006. Evidence that microRNAs are associated with translating messenger RNAs in human cells. Nat Struct Mol Biol 13: 1102-1107. doi:10.1038/ nsmb1174

Martinez G, Köhler C. 2017. Role of small RNAs in epigenetic reprogramming during plant sexual reproduction. Curr Opin Plant Biol 36: 22-28. doi:10.1016/j.pbi.2016.12.006

Martinez G, Choudury SG, Slotkin RK. 2017. tRNA-derived small RNAs target transposable element transcripts. Nucleic Acids Res 45: 5142-5152. doi:10.1093/nar/gkx103

Matzke MA, Mosher RA. 2014. RNA-directed DNA methylation: an epigenetic pathway of increasing complexity. Nat Rev Genet 15: 394-408. doi:10.1038/nrg3683

Matzke MA, Kanno T, Matzke AJM. 2015. RNA-directed DNA methylation: the evolution of a complex epigenetic pathway in flowering plants. Annu Rev Plant Biol 66: 243-267. doi:10.1146/annurevarplant-043014-114633
Mi S, Cai T, Hu Y, Chen Y, Hodges E, Ni F, Wu L, Li S, Zhou H, Long C, et al. 2008. Sorting of small RNAs into Arabidopsis argonaute complexes is directed by the $5^{\prime}$ terminal nucleotide. Cell 133: 116127. doi:10.1016/j.cell.2008.02.034

Mirouze M, Reinders J, Bucher E, Nishimura T, Schneeberger K, Ossowski S, Cao J, Weigel D, Paszkowski J, Mathieu O. 2009. Selective epigenetic control of retrotransposition in Arabidopsis. Nature 461: 427-430. doi:10.1038/nature08328

Montgomery TA, Howell MD, Cuperus JT, Li D, Hansen JE, Alexander AL, Chapman EJ, Fahlgren N, Allen E, Carrington JC. 2008. Specificity of ARGONAUTE7-miR390 interaction and dual functionality in TAS3 trans-acting siRNA formation. Cell 133: 128-141. doi:10.1016/j.cell.2008.02.033

Morel JB, Godon C, Mourrain P, Béclin C, Boutet S, Feuerbach F, Proux F, Vaucheret H. 2002. Fertile hypomorphic ARGONAUTE (ago1) mutants impaired in post-transcriptional gene silencing and virus resistance. Plant Cell Online 14: 629-639. doi:10 $.1105 /$ tpc.010358

Mosher RA, Melnyk CW, Kelly KA, Dunn RM, Studholme DJ, Baulcombe DC. 2009. Uniparental expression of PollV-dependent siRNAs in developing endosperm of Arabidopsis. Nature 460: 283-286. doi:10.1038/nature08084

Mustroph A, Juntawong P, Bailey-Serres J. 2009. Isolation of plant polysomal mRNA by differential centrifugation and ribosome immunopurification methods. Methods Mol Biol 553: 109-126. doi:10.1007/978-1-60327-563-7_6

Mustroph A, Zanetti ME, Girke T, Bailey-Serres J. 2012. Isolation and analysis of mRNAs from specific cell types of plants by ribosome immunopurification. Methods Mol Biol 959: 277-302. doi:10 .1007/978-1-62703-221-6_19

Nagano H, Fukudome A, Hiraguri A, Moriyama H, Fukuhara T. 2014. Distinct substrate specificities of Arabidopsis DCL3 and DCL4. Nucleic Acids Res 42: 1845-1856. doi:10.1093/nar/gkt1077

Peragine A, Yoshikawa M, Wu G, Albrecht HL, Poethig RS. 2004. SGS3 and SGS2/SDE1/RDR6 are required for juvenile development and the production of trans-acting siRNAs in Arabidopsis. Genes Dev 18: 2368-2379. doi:10.1101/gad.1231804

Pumplin N, Voinnet O. 2013. RNA silencing suppression by plant pathogens: defence, counter-defence and counter-counter-defence. Nat Rev Microbiol 11: 745-760. doi:10.1038/nrmicro3120

Pumplin N, Sarazin A, Jullien PE, Bologna NG, Oberlin S, Voinnet O. 2016. DNA methylation influences the expression of DICER-LIKE4 isoforms, which encode proteins of alternative localization and function. Plant Cell 28: 2786-2804. doi:10.1105/tpc.16.00554

Rajagopalan R, Vaucheret H, Trejo J, Bartel DP. 2006. A diverse and evolutionarily fluid set of microRNAs in Arabidopsis thaliana. Genes Dev 20: 3407-3425. doi:10.1101/gad.1476406

Rogers K, Chen X. 2013. Biogenesis, turnover, and mode of action of plant microRNAs. Plant Cell 25: 2383-2399. doi:10.1105/tpc.113 .113159

Roodbarkelari F, Du F, Truernit E, Laux T. 2015. ZLL/AGO10 maintains shoot meristem stem cells during Arabidopsis embryogenesis by down-regulating ARF2-mediated auxin response. BMC Biol 13: 74. doi:10.1186/s12915-015-0180-y

Scholthof HB, Alvarado VY, Vega-Arreguin JC, Ciomperlik J, Odokonyero D, Brosseau C, Jaubert M, Zamora A, Moffett P. 2011. Identification of an ARGONAUTE for antiviral RNA silencing in Nicotiana benthamiana. Plant Physiol 156: 1548-1555. doi:10 .1104/pp.111.178764

Slotkin RK, Vaughn M, Borges F, Tanurdžić M, Becker JD, Feijó JA, Martienssen RA. 2009. Epigenetic reprogramming and small RNA silencing of transposable elements in pollen. Cell 136: 461-472. doi:10.1016/j.cell.2008.12.038

Stalder L, Heusermann W, Sokol L, Trojer D, Wirz J, Hean J, Fritzsche A, Aeschimann F, Pfanzagl V, Basselet P, et al. 2013. 
The rough endoplasmatic reticulum is a central nucleation site of siRNA-mediated RNA silencing. EMBO J 32: 1115-1127. doi:10 .1038/emboj.2013.52

Stroud H, Greenberg MVC, Feng S, Bernatavichute YV, Jacobsen SE. 2013. Comprehensive analysis of silencing mutants reveals complex regulation of the Arabidopsis methylome. Cell 152: 352 364. doi:10.1016/j.cell.2012.10.054

Trapnell C, Pachter L, Salzberg SL. 2009. TopHat: discovering splice junctions with RNA-seq. Bioinformatics 25: 1105-1111. doi:10 .1093/bioinformatics/btp120

Tsukahara S, Kobayashi A, Kawabe A, Mathieu O, Miura A, Kakutani T. 2009. Bursts of retrotransposition reproduced in Arabidopsis. Nature 461: 423-426. doi:10.1038/nature08351

Tucker MR, Okada T, Hu Y, Scholefield A, Taylor JM, Koltunow AMG. 2012. Somatic small RNA pathways promote the mitotic events of megagametogenesis during female reproductive development in Arabidopsis. Development 139: 1399-1404. doi:10.1242/dev .075390

Várallyay E, Válóczi A, Ágyi A, Burgyán J, Havelda Z. 2010. Plant virusmediated induction of miR168 is associated with repression of ARGONAUTE1 accumulation. EMBO J 29: 3507-3519. doi:10 .1038/emboj.2010.215

Vaucheret H. 2008. Plant ARGONAUTES. Trends Plant Sci 13: 350 358. doi:10.1016/j.tplants.2008.04.007

Vazquez F, Legrand S, Windels D. 2010. The biosynthetic pathways and biological scopes of plant small RNAs. Trends Plant Sci 15: 337-345. doi:10.1016/j.tplants.2010.04.001

Voinnet O. 2009. Origin, biogenesis, and activity of plant microRNAs. Cell 136: 669-687. doi:10.1016/j.cell.2009.01.046

Wang X, Zhang S, Dou Y, Zhang C, Chen X, Yu B, Ren G. 2015. Synergistic and independent actions of multiple terminal nucleotidyl transferases in the $3^{\prime}$ tailing of small RNAs in Arabidopsis. PLoS Genet 11: e1005091-17. doi:10.1371/journal.pgen .1005091

Wen Y-Z, Zheng L-L, Liao J-Y, Wang M-H, Wei Y, Guo X-M, Qu L-H, Ayala FJ, Lun Z-R. 2011. Pseudogene-derived small interference RNAs regulate gene expression in African Trypanosoma brucei. Proc Natl Acad Sci 108: 8345-8350. doi:10.1073/pnas .1103894108

Wendte JM, Pikaard CS. 2017. The RNAs of RNA-directed DNA methylation. Biochim Biophys Acta 1860: 140-148. doi:10.1016/j .bbagrm.2016.08.004

Xia R, Xu J, Arikit S, Meyers BC. 2015. Extensive families of miRNAs and PHAS loci in Norway spruce demonstrate the origins of complex phasiRNA networks in seed plants. Mol Biol Evol 32: 29052918. doi:10.1093/molbev/msv164

Xiao J, Sekhwal MK, Li P, Ragupathy R, Cloutier S, Wang X, You FM. 2016. Pseudogenes and their genome-wide prediction in plants. Int J Mol Sci 17: 1991. doi:10.3390/ijms17121991
Xie Z, Allen E, Wilken A, Carrington JC. 2005. DICER-LIKE 4 functions in trans-acting small interfering RNA biogenesis and vegetative phase change in Arabidopsis thaliana. Proc Natl Acad Sci 102: 12984-12989. doi:10.1073/pnas.0506426102

Yang L, Wu G, Poethig RS. 2012. Mutations in the GW-repeat protein SUO reveal a developmental function for microRNA-mediated translational repression in Arabidopsis. Proc Natl Acad Sci 109: 315-320. doi:10.1073/pnas.1114673109

Ye R, Wang W, Iki T, Liu C, Wu Y, Ishikawa M, Zhou X, Qi Y. 2012. Cytoplasmic assembly and selective nuclear import of Arabidopsis Argonaute4/siRNA complexes. Mol Cell 46: 859870. doi:10.1016/j.molcel.2012.04.013

Zanetti ME, Chang IF, Gong F, Galbraith DW, Bailey-Serres J. 2005. Immunopurification of polyribosomal complexes of Arabidopsis for global analysis of gene expression. Plant Physiol 138: 624635. doi:10.1104/pp.105.059477

Zhai J, Zhang H, Arikit S, Huang K, Nan G-L, Walbot V, Meyers BC. 2015. Spatiotemporally dynamic, cell-type-dependent premeiotic and meiotic phasiRNAs in maize anthers. Proc Natl Acad Sci 112: 3146-3151. doi:10.1073/pnas.1418918112

Zhang X, Henriques R, Lin S-S, Niu Q-W, Chua N-H. 2006. Agrobacterium-mediated transformation of Arabidopsis thaliana using the floral dip method. Nat Protoc 1: 641-646. doi:10 $.1038 /$ nprot.2006.97

Zhang J-F, Yuan L-J, Shao Y, Du W, Yan D-W, Lu Y-T. 2008. The disturbance of small RNA pathways enhanced abscisic acid response and multiple stress responses in Arabidopsis. Plant Cell Environ 31: 562-574. doi:10.1111/j.1365-3040.2008.01786.x

Zhang X, Zhao H, Gao S, Wang W-C, Katiyar-Agarwal S, Huang H-D, Raikhel N, Jin H. 2011. Arabidopsis Argonaute 2 regulates innate immunity via miRNA393(*)-mediated silencing of a Golgi-localized SNARE gene, MEMB12. Mol Cell 42: 356-366. doi:10 .1016/j.molcel.2011.04.010

Zhang X, Zhang X, Singh J, Li D, Qu F. 2012. Temperature-dependent survival of turnip crinkle virus-infected Arabidopsis plants relies on an RNA silencing-based defense that requires DCL2, AGO2, and HEN1. J Virol 86: 6847-6854. doi:10.1128/JVI.00497-12

Zhang Z, Liu X, Guo X, Wang X-J, Zhang X. 2016. Arabidopsis AGO3 predominantly recruits 24 -nt small RNAs to regulate epigenetic silencing. Nat Plants 2: 16049. doi:10.1038/nplants.2016.49

Zhou Y, Honda M, Zhu H, Zhang Z, Guo X, Li T, Li Z, Peng X, Nakajima K, Duan L, et al. 2015. Spatiotemporal sequestration of miR165/166 by Arabidopsis argonaute10 promotes shoot apical meristem maintenance. Cell Rep 10: 1819-1827. doi:10 .1016/j.celrep.2015.02.047

Zhu H, Hu F, Wang R, Zhou X, Sze S-H, Liou LW, Barefoot A, Dickman M, Zhang X. 2011. Arabidopsis argonaute10 specifically sequesters miR166/165 to regulate shoot apical meristem development. Cell 145: 242-256. doi:10.1016/j.cell.2011.03.024 

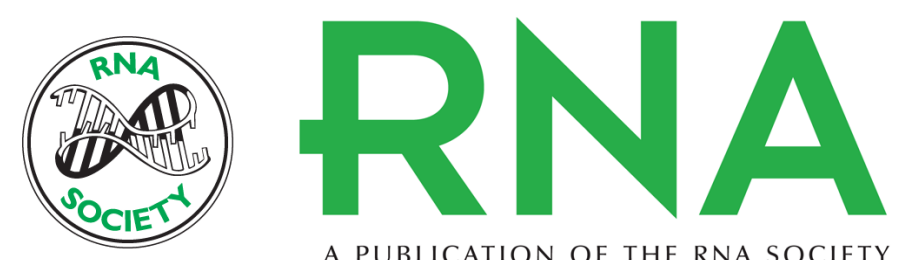

A PUBLICATION OF THE RNA SOCIETY

\section{Extensive profiling in Arabidopsis reveals abundant polysome-associated 24-nt small RNAs including AGO5-dependent pseudogene-derived siRNAs}

Antonin Marchais, Clément Chevalier and Olivier Voinnet

RNA 2019 25: 1098-1117 originally published online May 28, 2019

Access the most recent version at doi:10.1261/rna.069294.118

Supplemental Material

References

Creative Commons License

Email Alerting Service
http://rnajournal.cshlp.org/content/suppl/2019/05/28/rna.069294.118.DC1

This article cites 107 articles, 33 of which can be accessed free at: http://rnajournal.cshlp.org/content/25/9/1098.full.html\#ref-list-1

This article is distributed exclusively by the RNA Society for the first 12 months after the full-issue publication date (see http://rnajournal.cshlp.org/site/misc/terms.xhtml). After 12 months, it is available under a Creative Commons License (Attribution-NonCommercial 4.0 International), as described at http://creativecommons.org/licenses/by-nc/4.0/.

Receive free email alerts when new articles cite this article - sign up in the box at the top right corner of the article or click here.

\section{|||||||| Providing Precise Solutions for} your research.

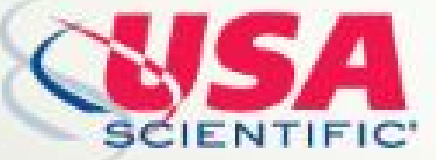

To subscribe to $R N A$ go to:

http://rnajournal.cshlp.org/subscriptions 